\title{
"Candidatus Chlorobium masyuteum," a Novel Photoferrotrophic Green Sulfur Bacterium Enriched From a Ferruginous Meromictic Lake
}

\begin{abstract}
Nicholas Lambrecht', Zackry Stevenson ${ }^{1}$, Cody S. Sheik ${ }^{2,3}$, Matthew A. Pronschinske', Hui Tong ${ }^{1,4}$ and Elizabeth D. Swanner ${ }^{1 *}$

${ }^{1}$ Department of Geological and Atmospheric Sciences, lowa State University, Ames, IA, United States, ${ }^{2}$ Department of Biology, University of Minnesota Duluth, Duluth, MN, United States, ${ }^{3}$ Large Lakes Observatory, University of Minnesota Duluth, Duluth, MN, United States, ${ }^{4}$ Guangdong Key Laboratory of Integrated Agro-environmental Pollution Control and Management, National-Regional Joint Engineering Research Center for Soil Pollution Control and Remediation in South China, Guangdong Institute of Eco-environmental Science and Technology, Guangdong Academy of Sciences, Guangzhou, China
\end{abstract}

OPEN ACCESS

Edited by: Lei Yan,

Heilongiiang Bayi Agricultural

University, China

Reviewed by:

Katharine J. Thompson,

University of British Columbia,

Canada

Petra Pjevac,

University of Vienna, Austria

*Correspondence: Elizabeth D. Swanner eswanner@iastate.edu

Specialty section: This article was submitted to Microbiological Chemistry and Geomicrobiology,

a section of the journal Frontiers in Microbiology

Received: 14 April 2021 Accepted: 07 June 2021 Published: 09 July 2021

Citation:

Lambrecht N, Stevenson Z, Sheik CS, Pronschinske MA, Tong H and Swanner ED (2021) "Candidatus

Chlorobium masyuteum," a Novel Photoferrotrophic Green Sulfur Bacterium Enriched From

a Ferruginous Meromictic Lake.

Front. Microbiol. 12:695260. doi: 10.3389/fmicb.2021.695260
Anoxygenic phototrophic bacteria can be important primary producers in some meromictic lakes. Green sulfur bacteria (GSB) have been detected in ferruginous lakes, with some evidence that they are photosynthesizing using $\mathrm{Fe}(\mathrm{II})$ as an electron donor (i.e., photoferrotrophy). However, some photoferrotrophic GSB can also utilize reduced sulfur compounds, complicating the interpretation of Fe-dependent photosynthetic primary productivity. An enrichment (BLA1) from meromictic ferruginous Brownie Lake, Minnesota, United States, contains an Fe(II)-oxidizing GSB and a metabolically flexible putative Fe(III)-reducing anaerobe. "Candidatus Chlorobium masyuteum" grows photoautotrophically with Fe(II) and possesses the putative Fe(II) oxidase-encoding cyc2 gene also known from oxygen-dependent Fe(II)-oxidizing bacteria. It lacks genes for oxidation of reduced sulfur compounds. Its genome encodes for hydrogenases and a reverse TCA cycle that may allow it to utilize $\mathrm{H}_{2}$ and acetate as electron donors, an inference supported by the abundance of this organism when the enrichment was supplied by these substrates and light. The anaerobe "Candidatus Pseudopelobacter ferreus" is in low abundance ( 1\%) in BLA1 and is a putative Fe(III)-reducing bacterium from the Geobacterales ord. nov. While "Ca. C. masyuteum" is closely related to the photoferrotrophs $C$. ferroooxidans strain KoFox and C. phaeoferrooxidans strain KB01, it is unique at the genomic level. The main light-harvesting molecule was identified as bacteriochlorophyll $c$ with accessory carotenoids of the chlorobactene series. BLA1 optimally oxidizes $\mathrm{Fe}(\mathrm{II})$ at a $\mathrm{pH}$ of 6.8 , and the rate of $\mathrm{Fe}(\mathrm{II})$ oxidation was $0.63 \pm 0.069$ mmol day ${ }^{-1}$, comparable to other photoferrotrophic GSB cultures or enrichments. Investigation of BLA1 expands the genetic basis for phototrophic $\mathrm{Fe}$ (II) oxidation by GSB and highlights the role these organisms may play in Fe(II) oxidation and carbon cycling in ferruginous lakes.

Keywords: photoferrotrophy, Brownie Lake, meromictic, green sulfur bacterium, phototrophic $\mathrm{Fe}$ (II) oxidation, early Earth biogeochemistry, iron cycling, geomicrobiology 


\section{INTRODUCTION}

Iron is a major redox-active element on Earth (Raiswell and Canfield, 2012). The biogeochemical cycling between the two main redox states, $\mathrm{Fe}(\mathrm{II})$ and $\mathrm{Fe}(\mathrm{III})$, is accomplished by both aerobic and anaerobic microbes, as well as abiotic chemical reactions (Melton et al., 2014). Active redox cycling mediated by microbes at the interface of oxic and anoxic settings couples the Fe biogeochemical cycles at Earth's surface to that of several other major elemental cycles (e.g., C, O, S, N; Kappler et al., 2021), underscoring the necessity to elucidate microbiological pathways that transform $\mathrm{Fe}$ and the controls on their activity in the environment.

Investigation of modern Fe cycling organisms may also help to constrain microbial processes in Precambrian (i.e., > 540 million years ago; $\mathrm{Ma}$ ) oceans, which were characterized by widespread and persistent ferruginous (anoxic and Fe-rich) conditions (Poulton and Canfield, 2011). Prior to the development of oxygenated surface waters after the Great Oxidation Event (GOE) at $\sim 2.4$ billion years ago (Ga), anoxygenic photosynthetic bacteria (APB) that could utilize $\mathrm{Fe}(\mathrm{II})$ in the photic zone may have been the major marine primary producers fueling the biosphere in the Archean (4.0-2.5 Ga), sustaining up to $10 \%$ of modern-day primary productivity prior to the evolution of oxygenic photosynthesis by Cyanobacteria (Canfield et al., 2006; Jones et al., 2015). These organisms, collectively known as photoferrotrophs, are bacteria that use light energy, Fe(II) as an electron donor, and inorganic carbon to perform anoxygenic photosynthesis (Ehrenreich and Widdel, 1994; Kappler et al., 2005):

$$
\begin{aligned}
& \text { light }(h v)+4 \mathrm{Fe}^{2+}+\mathrm{CO}_{2}+11 \mathrm{H}_{2} \mathrm{O} \\
& \rightarrow 4 \mathrm{Fe}(\mathrm{OH})_{3}+\left(\mathrm{CH}_{2} \mathrm{O}\right)+8 \mathrm{H}^{+}
\end{aligned}
$$

Photoferrotrophs have been implicated as major contributors to primary productivity in ferruginous Kabuno Bay of Lake Kivu (Llirós et al., 2015; Morana et al., 2016). They fix carbon in ferruginous Lake Svetloe (Savvichev et al., 2017). In ferruginous Lake La Cruz, photoferrotrophic activity was detected despite these organisms being only a small fraction of the APB community (Walter et al., 2014). However, the presence of sunlight and ferruginous conditions are not strong indicators that photoferrotrophy is occurring or is biogeochemically significant; increasing genomic evidence suggests photoferrotrophic APB are potentially widespread and active in many lakes (Tsuji et al., 2020; Garcia et al., 2021).

Photoferrotrophs are phylogenetically diverse and include the classes Alphaproteobacteria (purple non-sulfur bacteria, PNSB), Gammaproteobacteria (purple sulfur bacteria, PSB), and the family Chlorobiaceae within the class Chlorobia (green sulfur bacteria, GSB). Isolates or defined co-cultures of photoferrotrophs include the freshwater PNSB Rhodobacter ferrooxidans strain SW2 (Ehrenreich and Widdel, 1994) and Rhodopseudomonas palustris strain TIE-1 (Jiao et al., 2005); the PSB include the freshwater Thiodictyon sp. (Ehrenreich and Widdel, 1994; Croal et al., 2004) and the marine Rhodovulum robiginosom and Rhodovulum iodosum
(Straub et al., 1999); and the GSB include the marine Chlorobium sp. strain N1 enrichment (Laufer et al., 2017; Bryce et al., 2019), the freshwater Chlorobium ferrooxidans strain KoFox, which grows in coculture with Geospirillum sp. strain KoFum (Heising et al., 1999), the freshwater coculture of a strain closely related to Chlorobium ferrooxidans that grows in coculture with a strain closely related to Rhodopseudomonas palustris (Schmidt et al., 2021), and the isolate Chlorobium phaeoferrooxidans strain KB01 (Crowe et al., 2017). C. phaeoferrooxidans strain KB01 is the first photoferrotroph to be isolated from a ferruginous water column (Llirós et al., 2015).

In addition to $\mathrm{Fe}(\mathrm{II})$ oxidation, some APB can exploit sulfide as a photosynthetic electron donor (Straub et al., 1999; Laufer et al., 2017). APB utilize bacteriochlorophyll (Bchl) molecules and accessory pigments such as carotenoids to harvest light energy. Previous studies have documented the presence of Bchl $e$ and increased methylation of hopanoids under ferruginous conditions and attributed their presence to photoferrotrophic activity (Eickhoff et al., 2013; Crowe et al., 2014). The detection of degradation products of such biomolecules (e.g., biomarkers) in ancient rocks has been used as evidence for euxinic conditions, i.e., free sulfide present, in the Phanerozoic (e.g., Summons and Powell, 1986; Grice et al., 2005; Mallorquí et al., 2005; Hays et al., 2007) and Paleoproterozoic oceans (e.g., Brocks et al., 2005; Brocks and Schaeffer, 2008). However, specific pigments do not always indicate the electron donor being used [i.e., Fe(II) or sulfide] and, by implication, ferruginous or euxinic environmental conditions. Rather, the presence of these biomarkers establishes paleoenvironments in which light reached anoxic portions of ancient water columns, inferring the presence of obligate anoxygenic phototrophs. To fully understand and interpret the biomarker record, identification of potential biomarkers produced by diverse modern photoferrotrophs, especially those active under ferruginous conditions, is required.

Here, we describe the enrichment and characterization of a novel pelagic $\mathrm{Fe}$ (II)-oxidizing photoferrotroph from a meromictic and ferruginous lake that is closely related to other phototrophic GSB, but distinct in genomic and physiological characteristics. Similar to other photoferrotrophic GSB (Heising et al., 1999; Bryce et al., 2019; Schmidt et al., 2021), this organism could not be isolated, but is the most abundant organism in the enrichment. The characterization of novel photoferrotrophs informs the framework for understanding how APB, specifically GSB, influence carbon and iron cycling within ferruginous systems. The organism described here is only the second photoferrotroph to be brought into enrichment from a ferruginous water column, which highlights the difficulties, but also value, in bringing these organisms into culture.

\section{MATERIALS AND METHODS}

\section{Enrichment and Cultivation}

Freshwater from Brownie Lake in Minneapolis, Minnesota, United States, was taken from the chemocline $(5.5 \mathrm{~m})$ in 
May 2016. The field site and geochemical conditions have been described previously (Lambrecht et al., 2018). Site water $(1 \mathrm{ml})$ was added to Hungate tubes containing $9 \mathrm{ml}$ of freshwater (FW) medium amended with anoxic ferrous chloride $\left(\mathrm{FeCl}_{2}\right)$.

The FW medium for enrichment and cultivation had a salinity of 1.6. Per liter, the medium contained the following salts: $0.14 \mathrm{~g} \mathrm{KH}_{2} \mathrm{PO}_{4}, 0.3 \mathrm{~g} \mathrm{NH}_{4} \mathrm{Cl}, 0.5 \mathrm{~g} \mathrm{MgSO}_{4} \times 7 \mathrm{H}_{2} \mathrm{O}$, and $0.1 \mathrm{~g} \mathrm{CaCl}_{2} \times 2 \mathrm{H}_{2} \mathrm{O}$. The medium was degassed under $\mathrm{N}_{2} / \mathrm{CO}_{2}(90: 10 \mathrm{v} / \mathrm{v})$ and buffered with $22 \mathrm{mM} \mathrm{NaHCO}$ (1.85 $\left.\mathrm{g} \mathrm{l}^{-1}\right)$. Lastly, the following supplements were added in 1-ml volumes per liter: vitamin solution (1 mg biotin, $10 \mathrm{mg}$ nicotinate, $5 \mathrm{mg}$ aminobenzoic acid, $2.5 \mathrm{mg} \mathrm{Ca}-\mathrm{D}(+)$ pantothenate, $25 \mathrm{mg}$ pyridoxamine dihydrochloride, $5 \mathrm{mg}$ thiamine dihydrochloride, and $100 \mathrm{mg}$ vitamin $\mathrm{B}_{12}$ in $100 \mathrm{ml}$ Millipore water), selenium-tungstate solution $(0.4 \mathrm{~g} \mathrm{NaOH}$, $6 \mathrm{mg} \mathrm{Na} \mathrm{SeO}_{3} \times 5 \mathrm{H}_{2} \mathrm{O}$, and $8 \mathrm{mg} \mathrm{Na} \mathrm{WO}_{4} \times 2 \mathrm{H}_{2} \mathrm{O}$ in 11 Millipore water), and a trace element solution $(10 \mathrm{ml}$ of $25 \% \mathrm{HCl}, 2.86 \mathrm{~g} \mathrm{H}_{3} \mathrm{BO}_{3}, 0.5 \mathrm{~g} \mathrm{MnCl}_{2} \times 4 \mathrm{H}_{2} \mathrm{O}, 180 \mathrm{mg}$ $\mathrm{ZnCl}_{2}, 36 \mathrm{mg} \mathrm{Na} \mathrm{MoO}_{4} \times 2 \mathrm{H}_{2} \mathrm{O}, 2 \mathrm{mg} \mathrm{CuCl} 2 \times 2 \mathrm{H}_{2} \mathrm{O}$, $24 \mathrm{mg} \mathrm{NiCl} 2 \times 6 \mathrm{H}_{2} \mathrm{O}, 190 \mathrm{mg} \mathrm{CoCl}_{2} \times 6 \mathrm{H}_{2} \mathrm{O}$, and $1.5 \mathrm{~g}$ $\mathrm{FeCl}_{2} \times 4 \mathrm{H}_{2} \mathrm{O}$ in 11 Millipore water). The $\mathrm{pH}$ was adjusted using sterile anoxic $1 \mathrm{M} \mathrm{HCl}$ or $0.5 \mathrm{M} \mathrm{Na} \mathrm{CO}_{3}$ after autoclaving. Anoxic $\mathrm{FeCl}_{2}$, prepared according to Hegler et al. (2008), was subsequently added ( $\sim 3 \mathrm{mM}$ final conc.), and precipitation with phosphate and carbonate was allowed to occur at $4^{\circ} \mathrm{C}$ for $48 \mathrm{~h}$. Following precipitation, the media was filtered ( 0.2 polyethersulfone filter) in an anoxic chamber $(100 \%$ $\mathrm{N}_{2}$ ), dispensed in serum bottles, and the headspace promptly exchanged for $\mathrm{N}_{2} / \mathrm{CO}_{2}(90: 10 \mathrm{v} / \mathrm{v})$.

Enrichment was done at $20^{\circ} \mathrm{C}$ with illumination from two fluorescent bulbs, one warm $(2,700 \mathrm{~K})$ and one cool $(5,000$ $\mathrm{K})$, to provide the full spectrum of photosynthetically active radiation (PAR). Delivery of the full PAR spectrum from the two fluorescent bulbs was verified with a MSC15 spectral light meter (Gigahertz-Optik). A long-pass light filter (Edmund Optics) was initially used to allow only wavelengths longer than $700 \mathrm{~nm}$ to the tubes to exclude growth by oxygenic photosynthesis. After several months and four transfers, a series of two serial dilutions to extinctions were performed in an effort to isolate a single organism from the enrichment. A serial 10-fold dilution series prepared up to a dilution of $10^{-9}$. The last dilution showing evidence of $\mathrm{Fe}(\mathrm{II})$ oxidation was transferred. Following dilution to extinction, and for all experiments subsequently described, the enrichment was incubated with the full PAR spectrum. For standard cultivation, a $4 \%$ inoculum was used.

\section{DNA Sequencing and Bioinformatic Processing}

To identify which organisms were present in the enrichment before dilution to extinction, DNA was extracted using the DNeasy PowerSoil Kit (Qiagen) according to the instructions of the manufacturer. Near full-length 16S rRNA gene sequences were obtained using the universal bacterial primers $27 \mathrm{~F}$ $\left(5^{\prime}\right.$-AGAGTTTGATCCTGGCTCAG-3') and 1492R (5'-TA
CGGYTACCTTGTTACGACTT-3') (Lane, 1991). The PCR products were cloned into a plasmid vector with an ampicillin-resistant marker using the TOPO TA Cloning Kit (Thermo Fisher). Vectors were transformed into One Shot Top10 competent cells ThermoFisher (Waltham, MA, United States) that were afterward plated onto the LB medium containing ampicillin. Colonies were picked and tested for their correct size using the M13F (5'-CAGGAAACAGCTATGAC-3') and M13R (5'GTAAAACGACGGCCAG-3') primer pair. The PCR product with the correct insert was purified with the PureLink PCR purification kit (Invitrogen). Sanger sequencing was performed on an Applied Biosystems 3730xl DNA Analyzer at the ISU DNA Facility. All clones sequenced were aligned with ClustalW (Thompson et al., 2003).

For genome sequencing after dilution to extinction, DNA was extracted using the DNeasy PowerSoil Kit (Qiagen, Germantown, MD, United States) and sent to the University of Minnesota Genomics Core for sequencing. Sequencing libraries were created using the Nextera-XT kit (Illumina) and sequenced on the MiSeq platform with $2 \times 300$ bp paired-end sequencing. Prior to assembly, raw reads were trimmed of adapters and screened for quality with FastP (Chen et al., 2018). The cleaned reads were assembled with SPAdes v. 3.14.0 (Nurk et al., 2013). Genome quality was assessed using Quast (Gurevich et al., 2013). Searches of $16 \mathrm{~S}$ rRNA genes in the assembly with Barrnap (Seemann, 2018) revealed that the culture was not axenic and required genome binning. The assembly was binned with MetaBat1, Metabat2, and Maxbin2 (Kang et al., 2015; Wu et al., 2016; Kang et al., 2019). DASTool was used to select the highest-quality bins from the assemblies (Sieber et al., 2018). Genomes were assessed for completeness with CheckM (Parks et al., 2015) and taxonomy using GTDB-Tk (Chaumeil et al., 2019). The recovered genomes were genes called and annotated with MetaErg (Dong and Strous, 2019) and DRAM (Shaffer et al., 2020). FeGenie, a bioinformatics tool used to identify genes associated with $\mathrm{Fe}$ cycling, was used to screen the recovered genomes in the BLA1 enrichment for genes implicated in Fe cycling, specifically $\mathrm{Fe}(\mathrm{II})$ oxidation and $\mathrm{Fe}(\mathrm{III})$ reduction (Garber et al., 2020). The distance allowed between genes to be identified as a cluster was set to 5. A phylogenomic tree of the dominant recovered genomes with other closely related genomes was generated using GToTree (Lee, 2019). Genomes were downloaded from GTDB, and single-copy genes were identified with Hmmer ${ }^{1}$. Sixteen single-copy genes were used to assess the phylogenomic association (see Hug et al., 2016), as they have been shown to be robust for phylogenetic relationships. Prior to concatenation, the single-copy genes were individually aligned with Muscle (Edgar, 2004) and trimmed with trimAL (Capella-Gutiérrez et al., 2009). A maximum likelihood phylogenetic tree was created with IQ-TREE using default parameters (Nguyen et al., 2015). Genome relatedness of the Chlorobia genomes was assessed using Average Nucleotide Identity (ANI; Jain et al., 2018) and Digital DNA-DNA hybridization (DDH) with Genome-to-Genome Distance Tool (GGDC) (Meier-Kolthoff et al., 2013). The

${ }^{1}$ http://hmmer.org/ 
two genomes from this study were deposited to the National Center for Biotechnology Information (NCBI, Bioproject PRJNA611822) and the sequences to the sequence read archive (SRA; SRR11292469).

\section{Characterization of Growth Substrates Screening of Electron Donors}

The enrichment was tested on the following electron donors for anoxygenic phototrophic growth: acetate, hydrogen $\left(\mathrm{H}_{2}\right)$ gas, hydrogen sulfide, thiosulfate, and sulfite. Acetate was added at a final concentration of $5 \mathrm{mM}$. Hydrogen gas was supplied to the culture by flushing the headspace every second day with $\mathrm{H}_{2} / \mathrm{CO}_{2}$ gas $(90: 10 \mathrm{v} / \mathrm{v})$. The final concentrations of inorganic electron donors were as follows: sodium sulfide (2 mM), sodium thiosulfate $(2 \mathrm{mM})$, and sodium sulfite $(2 \mathrm{mM})$. Spectrophotometry at $600 \mathrm{~nm}$ was used to assess growth of the enrichment on alternative substrates.

\section{Growth Experiments With Fe(II)}

$\mathrm{Fe}(\mathrm{II})$ oxidation was tracked in two different types of experiments on the enrichment. The first was using triplicate bottles at different $\mathrm{pH}$ to determine the $\mathrm{pH}$ optimum. For this, three $50-\mathrm{ml}$ serum bottles were filled with $25 \mathrm{ml}$ of $\mathrm{Fe}$ (II) medium at each of the five initial $\mathrm{pH}$ conditions $(6.7,6.8,6.9,7.0$, and 7.1) set with the bicarbonate- $\mathrm{N}_{2} / \mathrm{CO}_{2}$ buffer system and capped with rubber butyl stoppers. PAR intensity was measured with a LI-190R quantum sensor coupled to a LI-250A light meter (LiCOR). Cultures were kept in a $20^{\circ} \mathrm{C}$ incubator at an intensity of $\sim 4 \mu \mathrm{M}$ photons $\mathrm{m}^{-2}$ $\mathrm{s}^{-1}$. Fe(II) was assessed on unfiltered samples acidified directly into $1 \mathrm{~N} \mathrm{HCl}$ and measured promptly with a ferrozine assay following a protocol adapted from Stookey (1970) and Viollier et al. (2000) using an Epoch 2 Microplate Reader (Biotek). The starting concentration of Fe(II) was $\sim 2.5 \mathrm{mM}$.

To determine cell-specific $\mathrm{Fe}(\mathrm{II})$ oxidation rates, triplicate 100 - $\mathrm{ml}$ bottles were filled with $50 \mathrm{ml} \mathrm{Fe}$ (II) medium adjusted to $\mathrm{pH}$ 6.8. Controls included dark conditions with cells and light without cells (control for photo-oxidation). Fe(II) concentrations were tracked as above. For growth quantification, samples were extracted and immediately fixed with paraformaldehyde (final conc. $3.8 \%$ ) and stored at $4^{\circ} \mathrm{C}$. Fe-oxide digestion and filtration onto black filters were conducted following Wu et al. (2014). Cells were stained with Sytox (1:50 dilution). Fluorescent images were collected using a Leica DFC7000T microscope. Twenty fields of view or 1,000 cells were enumerated for each replicate at each time point. Cell counting was aided by the $3 \mathrm{D}$ Objects Counter from ImageJ (Abràmoff et al., 2004). The maximum rate of $\mathrm{Fe}$ (II) oxidation was calculated for each replicate by linear regression of the steepest part of their respective $\mathrm{Fe}(\mathrm{II})$ vs. time plots (minimum three points).

\section{Photosynthetic Pigment Identification Pigment Extraction}

Pigment extraction was performed following an in-house protocol created by the Metabolomics Lab at ISU based on published protocols (Costas et al., 2012; Bóna-Lovász et al., 2013). The enrichment was grown with ferrous iron, in stationary phase, and was centrifuged at 1,000 rpm for $15 \mathrm{~min}$ followed by removal of the supernatant. An acetone/methanol solution $(7: 2 \mathrm{v} / \mathrm{v})$ was added to the spun-down cells and sonicated in a water bath for $10 \mathrm{~min}$, then vortexed for $10 \mathrm{~min}$ at maximum speed. After centrifugation at 1,000 rpm for $10 \mathrm{~min}$, the supernatant containing the pigments was transferred to a clean tube and dried under a constant stream of $\mathrm{N}_{2}$ gas. Once dried, concentrated pigments were resuspended in $\sim 0.4 \mathrm{ml}$ of the acetone/methanol solution.

\section{UHPLC and MS(n) Analysis}

Concentrated Bchl compounds were detected and quantified using the Agilent 6540 UHD Q-TOF LC/MS system. Chromatographic separation was performed using an Agilent 1290 Infinity series UHPLC, equipped with a diode array detector. A Zorbex Eclipse Plus C18 RRHD column $(2.1 \times 100 \mathrm{~mm}, 1.8 \mu \mathrm{m})$ was used to separate the isolated sample. Temperature during separation was held at $45^{\circ} \mathrm{C}$. Analysis was performed using a $10-\mu 1$ injection of sample and a flow rate of $0.5 \mathrm{ml} \mathrm{min}-1$. The mobile phase consisted of Solvent A, a 7:2:1 (water:methanol:acetonitrile) mixture, and Solvent B, a 3:1:1 (acetonitrile:MTBE:methanol) mixture. A gradient starting from $60 \% \mathrm{~A}$ and $40 \% \mathrm{~B}$ was followed by $25 \% \mathrm{~A}$ and $75 \% \mathrm{~B}$ for $5 \mathrm{~min}$, and then $100 \% \mathrm{~B}$ for $15 \mathrm{~min}$. After, the sample was held for $20 \mathrm{~min}$. This was followed by a return to initial conditions $(60 \% \mathrm{~A}, 40 \% \mathrm{~B})$ held for a 6 -min post-analysis equilibration. All spectra were captured at a range of absorbance from 300 to $950 \mathrm{~nm}$, by a step of $4 \mathrm{~nm}$, and a $0.62-\mathrm{Hz}$ scan rate.

MS/MS analysis was performed using the Agilent 6540 UHD Q-Tof Mass Spectrometer, operating in positive ion mode. Mass spectra were obtained using the Agilent QTOF 6540 mass spectrometer equipped with the JetStream ESI ion source. The mass spectrometer was scanned from $\mathrm{m} / \mathrm{z} 100$ to 1,700 and operated in the $4-\mathrm{GHz}$ HRes mode. Accurate mass measurement was achieved by constantly infusing a reference calibrant (ions at $\mathrm{m} / \mathrm{z} 121.0508$ and 922.0098). An Agilent Technologies 1100 Series HPLC system coupled to an Agilent Technologies Mass Selective Trap SL detector equipped with an atmospheric pressure chemical ionization source was used for $\mathrm{MS}^{5}$ analysis of selected Bchl molecules using directed infusion. All pigments were identified by comparison with published reference absorption spectra (Jensen, 1965; Airs and Keely, 2002).

\section{Microscopy}

A 2- $\mu$ l aliquot from the enrichment grown with $\mathrm{Fe}$ (II) was placed onto a carbon film grid (Electron Microscopy Sciences) and allowed to settle for $1 \mathrm{~min}$. After additional liquid was wicked from the grid, $2 \mu \mathrm{l}$ of aqueous $2 \%$ uranyl acetate was immediately added and allowed $30 \mathrm{~s}$ to fully immerse the grid. Following a final wick of the grid, it was allowed to dry leaving a thin film of cells. Transmission electron microscopy (TEM) images were obtained using JEOL 2100 STEM in the Roy J. Carver High Resolution Microscopy facility at ISU. The images were captured under normal high vacuum conditions at $200 \mathrm{kV}$ with a Gatan OneView $4 \mathrm{~K}$ camera. Fluorescence images were obtained as described in section "Growth Experiments With Fe(II)." 


\section{RESULTS AND DISCUSSION}

\section{Enrichment of BLA1}

Initial enrichment of lake water from the chemocline on FW medium containing $\mathrm{Fe}(\mathrm{II})$ with a long-pass light filter resulted in growth as assessed by visible $\mathrm{Fe}(\mathrm{II})$ oxidation and precipitation. After dilution-to-extinction and propagation for several generations, DNA was extracted, and the 16S rRNA gene was amplified and cloned to identify dominant taxa in the enrichment. All clones sequenced (17 of 17) were identical and had close matches to photoferrotrophic GSB.

Metagenomics was then performed on the enrichment after dilution to extinction. The number of assembled contigs and total size of the assembly suggested more than one genome may be present. Searches of assembled 16S rRNA genes with Barrnap ${ }^{2}$ revealed two unique $16 \mathrm{~S}$ rRNA sequences. The enrichment was subsequently named "BLA1," as the first enrichment (A1) from Browne Lake (BL), and this epithet is applied to the dominant strain within the enrichment. The dominant genome $(\sim 300 \times$ coverage $)$ was predicted to be $99 \%$ complete with $0 \%$ contamination. Taxonomic identification of the genome bin with GTDB-TK identified it as a novel species belonging to the Chlorobium genus based on average nucleotide differences. The 16S rRNA gene from the Chlorobium sp. BLA1 genome matched $100 \%$ by BLAST (Altschul et al., 1990) to the $16 \mathrm{~S}$ rRNA clones which initially recovered "BLA1" enrichment. The recovered Chlorobium sp. BLA1 genome was closely related to other known photoferrotrophic GSB, particularly C. ferrooxidans and C. phaeoferrooxidans KB01 (Figure 1). The second and less abundant genome $(4 \times$ coverage $)$ was $97 \%$ complete with $2 \%$ contamination. Pseudopelobacter sp. SKOL is taxonomically associated with the novel order Geobacterales and novel family Pelobacteraceae (Figure 2; Waite et al., 2020). GTDB-TK identified the genome as a novel species within the Pseudopelobacter genus and is similar to a preexisting genome, Pseudopelobacter sp001802125 (GTDB taxonomy, NCBI name GWC2_55_20).

\section{Morphology and Growth of BLA1}

TEM revealed that the dominant cell type in BLA1 was rodshaped, ca. $0.8-0.9 \mu \mathrm{m}$ long and $0.4-0.6 \mu \mathrm{m}$ wide (Figure 3). Cells did not contain flagella and are immotile, consistent with all other photoferrotrophs assessed for motility (Ehrenreich and Widdel, 1994; Heising et al., 1999; Straub et al., 1999). Cell morphology appeared similar to C. ferrooxidans strain KoFox (Heising et al., 1999).

The $\mathrm{pH}$ optimum for BLA1 growth on $\mathrm{Fe}(\mathrm{II})$ was $\mathrm{pH} 6.8$ as determined by the $\mathrm{Fe}(\mathrm{II})$ oxidation rate (Figure 4). This is similar to the optimum for other photoferrotrophs (Straub et al., 1999), although a freshwater photoferrotrophic Chlorobium sp. isolated from Lake Constance had an optimum of pH 7.4-7.6 (Schmidt et al., 2021). Protons are a product of Eq. 1, which likely explains the preference of many photoferrotrophs for circumneutral $\mathrm{pH}$. The $\mathrm{pH}$ of water decreases with depth through the chemocline of Brownie Lake and is seasonally variable, but is generally from 8

${ }^{2}$ https://github.com/tseemann/barrnap near the epilimnion down to 6.5 near the monimolimnion. Fe(II) oxidation rates were slowest at $\mathrm{pH} 7.0$ (Figure 4), indicating that ideal conditions for this organism and Fe(II) oxidation may occur near the bottom of the chemocline.

The rate of $\mathrm{Fe}(\mathrm{II})$ oxidation in other photoferrotrophic organisms has also been shown to increase with higher Fe(II) concentrations and increasing light intensity (e.g., MichaelisMenten kinetics; Hegler et al., 2008; Wu et al., 2014; Laufer et al., 2017). The effect of these additional factors on Fe(II) oxidation rate was not explored here. However, PAR in the chemocline of Brownie Lake varied from a maximum of 1-2 $\mu$ mol photons $\mathrm{m}^{-2} \mathrm{~s}^{-1}$ at the top of the chemocline down to 0.1 $\mu$ mol photons $\mathrm{m}^{-2} \mathrm{~s}^{-1}$. Such conditions are consistent with GSB being able to inhabit some of the lowest light environments of all photosynthetic bacteria (Overmann and Garcia-Pichel, 2013).

Iron oxidation was followed in triplicate incubations at $\mathrm{pH}$

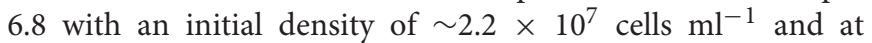
a light intensity of $4.2 \mu \mathrm{mol}$ photons $\mathrm{m}^{-2} \mathrm{~s}^{-1}$. Serum bottles of FW medium containing $\mathrm{Fe}$ (II) showed evidence of $\mathrm{Fe}$ (II) oxidation after 8-10 days. No oxidation of Fe(II) was observed in cultures incubated in the dark or in uninoculated samples incubated in the light (Figure 4). The average rate of $\mathrm{Fe}(\mathrm{II})$ oxidation at $20^{\circ} \mathrm{C}$ and $4.2 \mu \mathrm{M}$ photons $\mathrm{m}^{-2} \mathrm{~s}^{-1}$ was $0.63 \pm 0.069$ mmol day ${ }^{-1}$. After 16 days, 95\% of the Fe(II) was oxidized. The Fe(II) oxidation rate of BLA1 is commensurate with other photoferrotrophic enrichments containing Chlorobium sp., such as the marine Chlorobium sp. strain N1, $0.77 \pm 0.02 \mathrm{mmol} \mathrm{day}^{-1}$ (Laufer et al., 2017). It is also similar to the freshwater purple nonsulfur R. ferrooxidans strain SW2, $0.40 \mathrm{mM}^{\text {day }}{ }^{-1}$ (Kappler et al., 2005). Cell numbers increased under Fe(II) growth conditions to $3.8 \times 10^{8}$ cells $\mathrm{ml}^{-1}$ at day 16 (Figure 4 ). The doubling time during $\mathrm{Fe}(\mathrm{II})$ oxidation was 0.6 days $(14.3 \mathrm{~h})$. This doubling time is comparable to Chlorobium sp. strain N1 (0.4 days or 9.6 h; Laufer et al., 2017) but is faster than C. ferrooxidans strain KoFox (5.3 days; Heising et al., 1999). At $3.8 \times 10^{8}$ cells ml $^{-1}$, the average cell-specific $\mathrm{Fe}(\mathrm{II})$ oxidation rate for Chlorobium sp. BLA1 was $1.68 \pm 0.26 \mathrm{fmol} \mathrm{cell}^{-1} \mathrm{day}^{-1}$. This is comparable to Chlorobium sp. strain N1 (1.15 fmol cell ${ }^{-1}$ day $^{-1}$; Laufer et al., 2017), but $\sim 1,000 \times$ lower than for photoferrotrophs inhabiting the chemocline of Kabuno Bay (1.25 pmol cell ${ }^{-1}$ day $^{-1}$; Llirós et al., 2015).

Similar to many other enriched or isolated photoferrotrophic Chlorobium sp., the BLA1 enrichment did not show evidence for growth with reduced sulfur compounds (Table 1). The exception is Chlorobium sp. N1, which was enriched from marine sediments (Laufer et al., 2017) where sulfur compounds are generally more abundant than lake water. Chlorobium sp. from ferruginous lakes have sometimes also been determined to have the capacity for photosynthetic oxidation of both $\mathrm{Fe}(\mathrm{II})$ and reduced sulfur compounds (Crowe et al., 2014; Tsuji et al., 2020), perhaps indicating that selection for and utilization of photoferrotrophy in the environment is dependent on the specific environmental conditions, such as low sulfur. Brownie Lake, from which BLA1 was enriched, does have 50-100 $\mu \mathrm{M}$ sulfate and hydrogen sulfide is periodically detected in anoxic water (Lambrecht et al., 2018).

The BLA1 enrichment was able to grow with both $\mathrm{H}_{2}$ and acetate (Table 1). This finding is very similar to a freshwater 


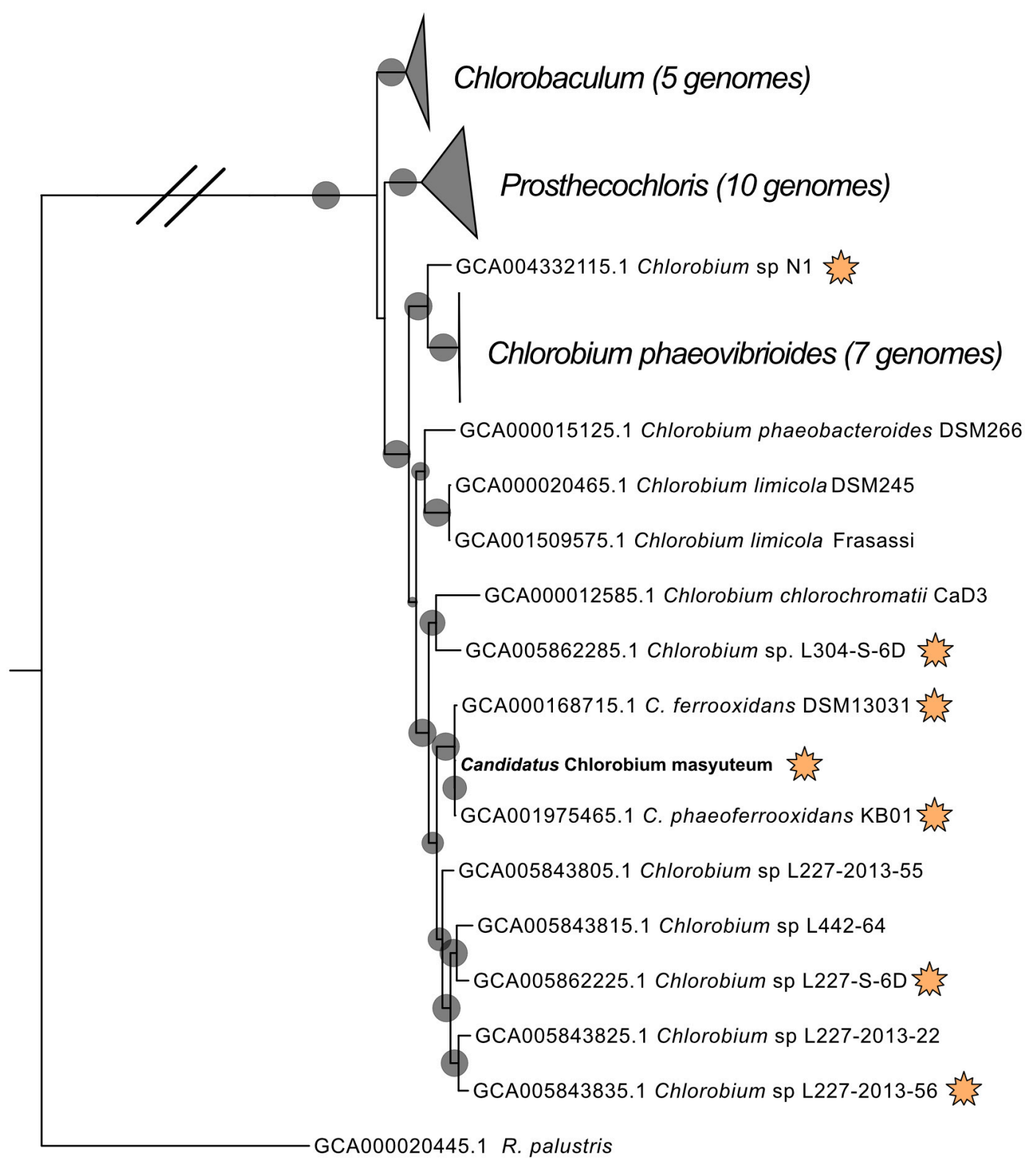

Tree scale: 0.1

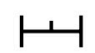

FIGURE 1 | Phylogenomic tree of "Ca. C. masyuteum" with other Chlorobia isolates and metagenome assembled genomes. Genomes highlighted with orange stars are either experimentally verified or inferred from the genome to photo-oxidize Fe(II). Bootstrap values (>75\%) are represented by black circles. Orange stars represent organisms with either tested or inferred photoferrotrophy capability.

enrichment of a photoferrotrophic Chlorobium sp. with a photosynthetic Rhodopseudomonas sp. (Schmidt et al., 2021). In that study, detailed experiments and subsequent isolation of the Rhodopseudomonas sp. revealed that while only the Chlorobium sp. was capable of photosynthetic Fe(II) oxidation, both strains were capable of $\mathrm{H}_{2}$ oxidation, and only the Rhodopseudomonas sp. was capable of growth using acetate (Table 1). For BLA1, observable growth on $\mathrm{H}_{2}$ was seen approximately 10-14 days following inoculation, and growth on acetate often required a lag time of 8-14 days. Direct Sanger sequencing of the 16S rRNA gene amplified from DNA extracted when BLA1 was grown with $\mathrm{H}_{2}$ or acetate resulted in a clean sequence matching of the $16 S$ rRNA recovered from the Chlorobium sp. BLA1 genome, suggesting robust growth by that organism on these substrates.

Nevertheless, there is the possibility for a close relationship with the Pseudopelobacter sp., much like what was observed by Schmidt et al. (2021) in their enrichment. It seems unlikely to involve simultaneous Fe(III) reduction by Pseudopleobacter sp. 


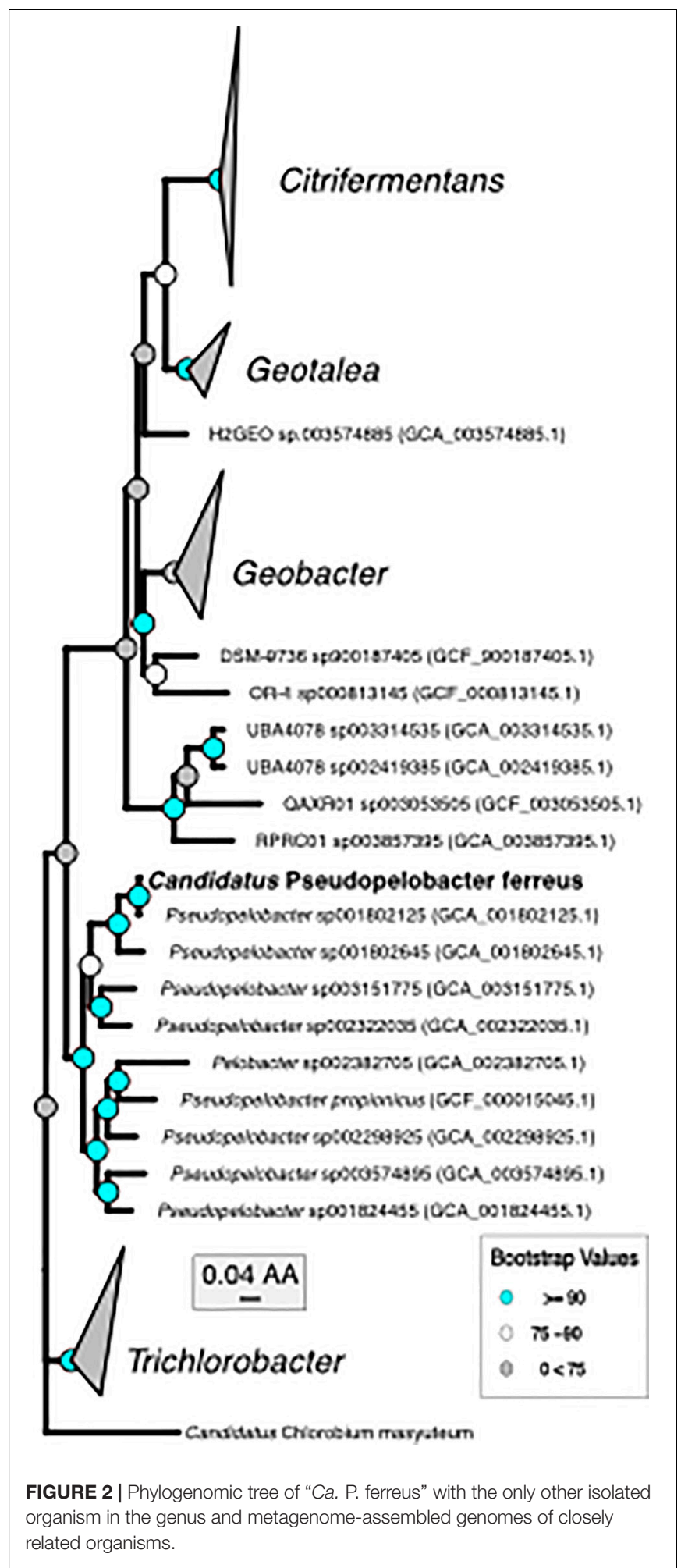

SKOL during $\mathrm{Fe}$ (II) oxidation in the absence of acetate (see below for a discussion of functional capabilities encoded in both genomes) as no $\mathrm{Fe}(\mathrm{III})$ reduction was observed after all $\mathrm{Fe}(\mathrm{II})$ had been oxidized (Supplementary Figure 1). However, acetate and formate are detectable in the chemocline of Brownie Lake, suggesting redox cycling of $\mathrm{Fe}$ between these two organisms could be possible. No $\mathrm{H}_{2}$ measurements have been made in Brownie Lake.

\section{Phylogenomics of BLA1 Enrichment Genomes}

Chlorobium sp. BLA1 is > 99\% similar by the $16 \mathrm{~S}$ rRNA gene to C. ferrooxidans and C. phaeoferrooxidans, and the three genomes are similar in size, \%GC, and gene number (Table 2). This result is congruent with the phylogeny of sequenced genomes (Figure 1). All three of these strains are genetically distinct from other anoxygenic phototrophic Chlorobia that lack the ability to oxidize Fe(II). For instance, the Chlorobium sp. BLA1 16 S rRNA sequence is only $97 \%$ similar to that of Chlorobium clathratiforme. Therefore, to distinguish whether Chlorobium sp. BLA1 is a new species or a subspecies of either C. ferrooxidans or C. phaeoferrooxidans, we used two independent measures of genome relatedness, digital DNA-DNA hybridization (DDH) and average nucleotide identity (ANI). Both DDH and ANI values indicate that Chlorobium sp. BLA1 is a novel species (Table 2). DDH values for all the closest related genomes were well below the accepted cutoff of 70\% (Meier-Kolthoff et al., 2013). Additionally, ANI values for these genomes were also below the 95\% cutoff for species level (Jain et al., 2018). These results indicate that at the genome level, Chlorobium sp. BLA1 is sufficiently divergent from C. ferrooxidans and C. phaeoferrooxidans to be considered a distinct species. Thus, we assign the name "Candidatus Chlorobium masyuteum."

The second organism, Pseudopelobacter sp. SKOL, is taxonomically associated with the Order Geobacterales and was far less abundant in the assembly $(4 \times$ coverage $)$. The genome is most closely related to Pseudopelobacter sp001802645 (95.5\% similar by ANI), a metagenome-assembled genome (MAG) from groundwater in Rifle, CO (Anantharaman et al., 2016). Currently, there is one isolated species, Pseudopelobacter propionicus, from this proposed genus. We propose the name "Candidatus Pseudopelobacter ferreus."

\section{Predicted Functional Capability of BLA1 Genomes "Candidatus Chlorobium masyuteum"}

The "Ca. C. masyuteum" genome consists of 17 contigs, with 2,312 predicted genes, and two rRNA operons. Gene and protein families predicted to function in key physiological activities of "Ca. C. masyuteum" are presented in Figure 5A. As with other members of the class Chlorobia, "Ca. C. masyuteum" has a type 1 photosynthetic reaction center (RC). Chlorosomes are unique membrane-bound photosynthetic antenna complexes found exclusively in GSB that contain large numbers of Bchl molecules (Imhoff, 2014). Chlorosome genes (csmE, csmAC, $\operatorname{csm} B$, and $\operatorname{csm} I J)$ appeared on four separate contigs. The fmoA gene encoding for the Fenna-Matthews-Olson protein are also present. The Fenna-Matthews-Olson protein participates in energy transfer from chlorosomes to the RC in the Chlorobiaceae (Fenna et al., 1974). Chlorobiales synthesize Bchl $a$ and $\mathrm{Chl} a$, as 


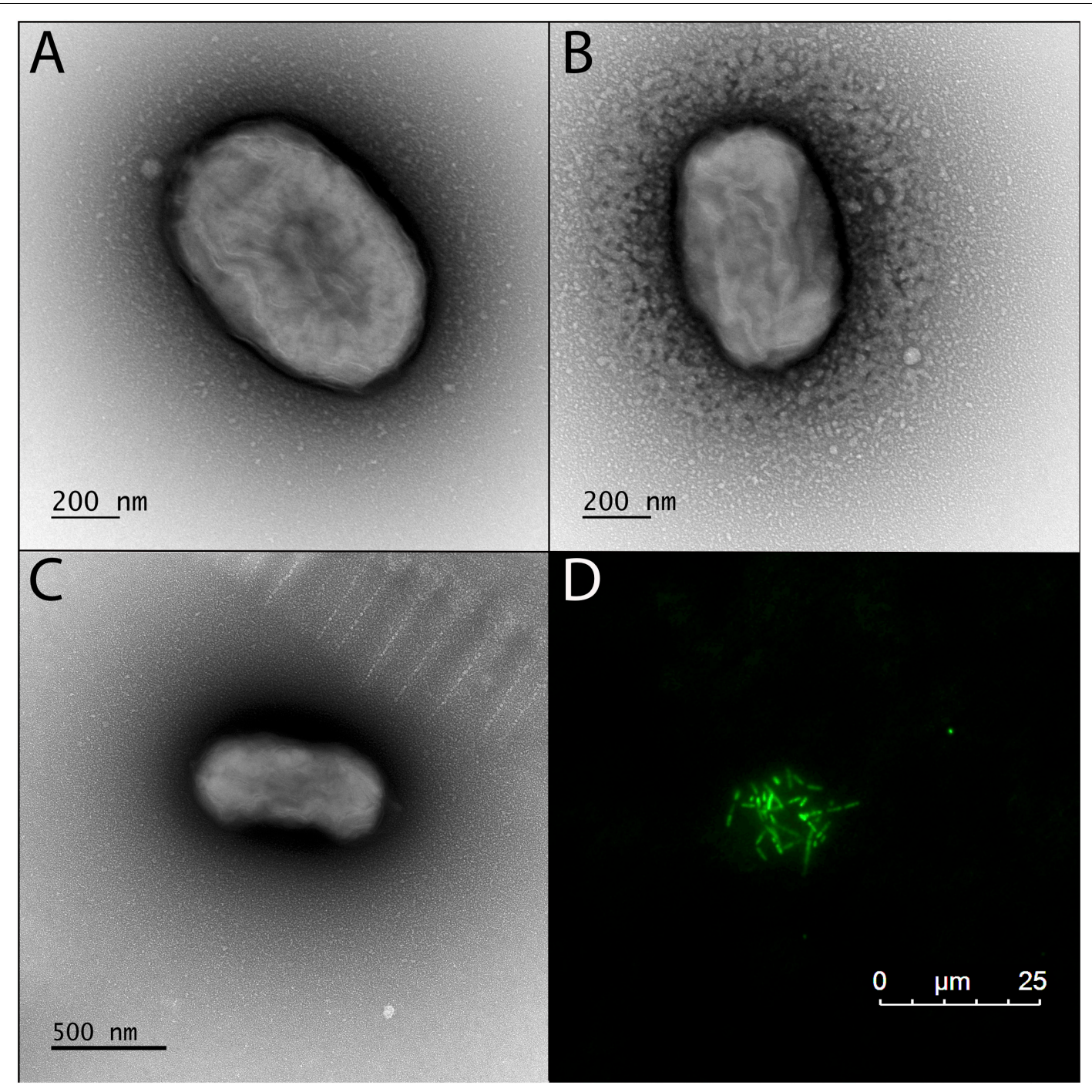

FIGURE 3 | Transmission electron microscopy (TEM) and fluorescence microscope images of the BLA1 enrichment grown in FW medium with Fe(II). (A-C) TEM; cell surfaces appear wrinkled, while still maintaining the structure of the cell, due to dehydration during TEM preparation. (D) Fluorescence image of live cells clustered on an Fe(III) mineral.

well as major Bchl $(c, d$, or $e$ ) to harvest light (Bryant and Liu, 2013). The genome of “Ca. C. masyuteum" contained at least six protein families corresponding to the synthesis of Bchl $a$ and two corresponding to $\mathrm{Chl} a$ synthesis (Figure 5A and Supplementary Table 1). Additionally, two protein families specific to the Bchl $c$ synthesis pathway, BchU and BchV, were present (Maresca et al., 2004; Chew, 2007).

The functional hallmark of the BLA1 enrichment is the ability to grow photoautotrophically using $\mathrm{Fe}(\mathrm{II})$. In photoferrotrophic purple bacteria, the pioABC operonis a three-gene operon coding for a periplasmic decaheme c-type cytochrome that transfers electrons ( $p i o A)$, an outer membrane $\beta$-barrel protein $(p i o B)$, and a periplasmic high potential iron-sulfur cluster protein that participates in anaerobic electron transport ( $p i o C$; Jiao and Newman, 2007). This operon is found in R. vannielii strain ATCC 17100 (He et al., 2017) and $R$. palustris
(Jiao and Newman, 2007). The foxEYZ operonis another threegene operon that encodes for a c-type cytochrome (foxE), a putative protein containing the cofactor pyrroloquinoline (foxY), and a putative protein with transport function (foxZ) and is found in R. ferrooxidans (Croal et al., 2007). Annotation of the "Ca. C. masyuteum" genome indicates that the pio and fox operons are absent. This finding is similar to other GSB photoferrotrophs (Bryce et al., 2018; Tsuji et al., 2020), leading us to screen for other genes with potential Fe(II) oxidase activity.

Recently, homologs to an outer-membrane c-type cytochrome that functions in $\mathrm{Fe}(\mathrm{II})$ oxidation, encoded by the gene $c y c 2$, have been detected in both acidophilic and neutrophilic oxygen-dependent $\mathrm{Fe}(\mathrm{II})$ oxidizing bacteria. Acidothiobacillus ferrooxidans, Mariprofundus sp., Acidothiobacillus ferrooxidans, Mariprofundus sp., Gallionellaceae, and Zetaproteobacteria are 

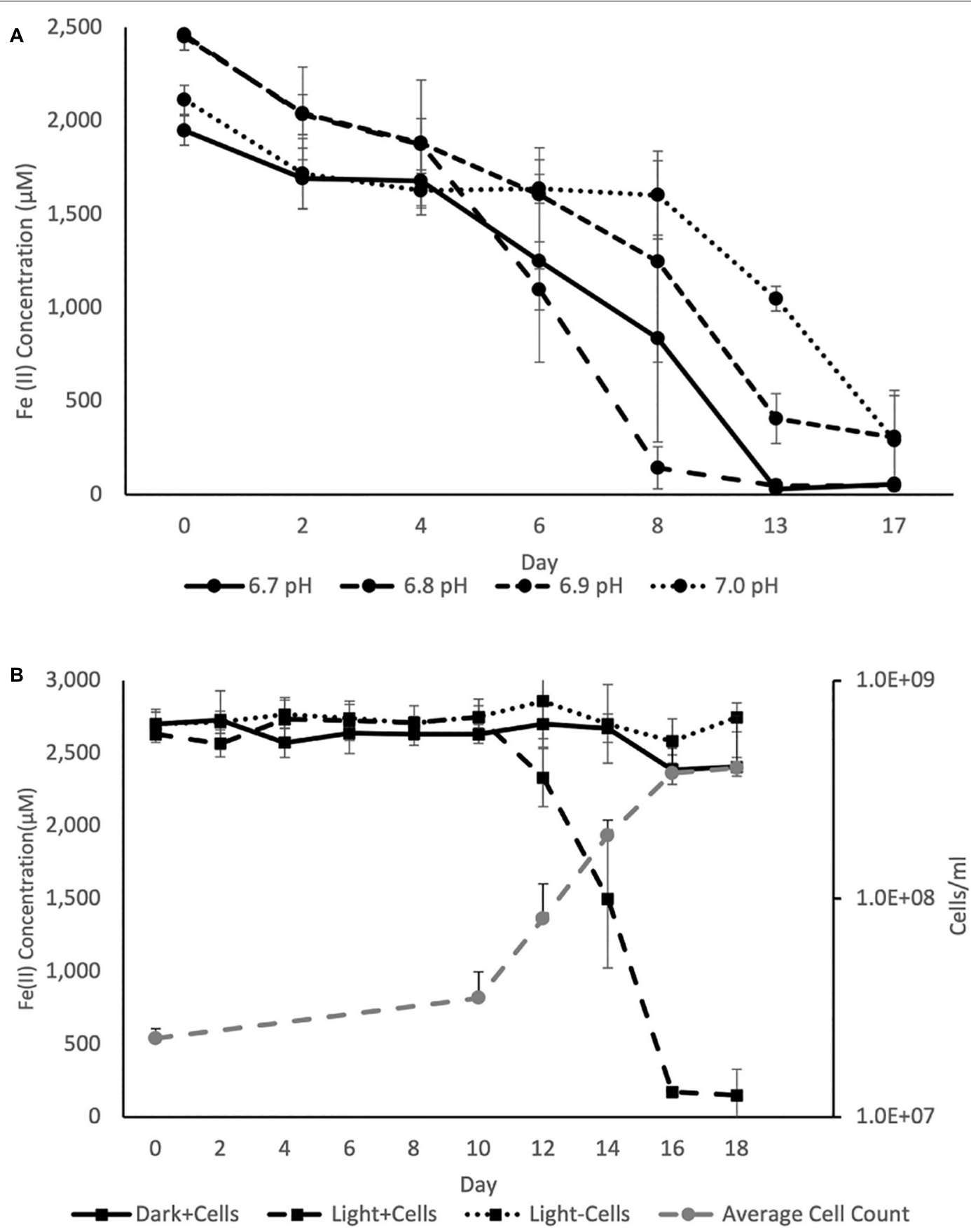

FIGURE 4 | (A) Average Fe(II) oxidation curves for triplicate BLA1 incubations under illumination at different pH, showing optimal activity at pH 6.8. (B) Representative growth and Fe(II) oxidation of BLA1 from one triplicate. Error bars represent the standard deviation of analytical triplicates for Fe(II) (in all cases smaller than symbol size) and the standard deviation of all fields of view counted for cell counts.

such examples (Castelle et al., 2008; Barco et al., 2015; Chan et al., 2018; McAllister et al., 2020). Subsequently, the cyc2 gene was found in the genomes of $C$. ferrooxidans and $C$. phaoferrooxidans (He et al., 2017; Chan et al., 2018) and have been detected in Chlorobium metagenomes in enrichments from ferruginous lakes (Tsuji et al., 2020). We identified cyc2 in the genome of " $\mathrm{Ca}$. C. masyuteum." In addition, we identified two genes, $a f u B C$, which are integral and cytoplasmic membrane proteins of the ferric iron $\mathrm{ABC}$ transport system in "Ca. C. masyuteum" (Figure 5A).

The BLA1 enrichment was not able to oxidize sulfide, sulfite, or thiosulfate (Table 1). The "Ca. C. masyuteum" genome was in agreement with growth experiments, as genes implicated in sulfide $(d s r)$ or thiosulfate $(s o x)$ oxidation were absent (Figure 5A). This differs from the GSB Chlorobium sp. strain N1 
TABLE 1 | Commonly used sole organic and inorganic electron donors to assess additional photoautotrophic growth of true photoferrotrophic isolates or enrichments.

\begin{tabular}{|c|c|c|c|c|c|c|}
\hline Photoferrotroph & Iron(II) & Acetate & Hydrogen & Sulfide & Thiosulfate & Source \\
\hline "Ca. C. masyuteum" & + & $(+)$ & $(+)$ & - & - & This study \\
\hline \multirow[t]{2}{*}{ C. ferrooxidans strain KoFox } & + & - & + & - & - & Heising et al., 1999 \\
\hline & & & & & & Hegler et al., 2008 \\
\hline C. phaeoferrooxidans strain KB01 & + & n. d. & n. d. & n. d. & n. d. & Crowe et al., 2017 \\
\hline Chlorobium sp. & + & $(+)$ & + & - & - & Schmidt et al., 2021 \\
\hline Chlorobium sp. strain N1 & + & + & + & + & + & Laufer et al., 2017 \\
\hline \multirow[t]{2}{*}{ Thiodycton sp. strains Thd2 and F4 } & + & + & + & - & - & Ehrenreich and Widdel, 1994 \\
\hline & & & & & & Hegler et al., 2008 \\
\hline R. palustrisstrain TIE-1 & + & + & + & - & + & Jiao et al., 2005 \\
\hline R. ferrooxidansstrain SW2 & + & + & + & - & n. d. & Ehrenreich and Widdel, 1994 \\
\hline R. iodosum & + & + & + & + & + & Straub et al., 1999 \\
\hline R. rubiginosum & + & + & + & + & + & Straub et al., 1999 \\
\hline
\end{tabular}

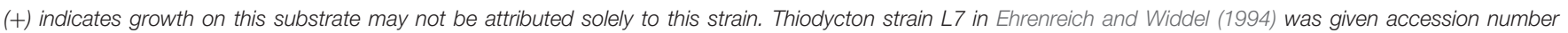
X78718, and this accession number in GenBank recognizes this isolate as strain Thd2. n.d. = no data.

TABLE 2 | Isolate genome characteristics and comparisons to other Chlorobia genomes.

\begin{tabular}{|c|c|c|c|c|c|c|c|}
\hline Reference genome & Strain name & DDH & Model C.I. (\%) & ANI & $\%$ GC & Genome size (Mb) & No. genes \\
\hline "Ca. Chlorobium masyuteum" & BLA1 & - & - & - & 50.6 & 2.56 & 2,312 \\
\hline Chlorobium ferrooxidans & DSM 13031 & 54.8 & $52.1-57.5$ & 94.1 & 50.1 & 2.54 & 2,308 \\
\hline Chlorobium phaeoferrooxidans & KB01 & 51.5 & $48.9-54.2$ & 93.4 & 49.7 & 2.57 & 2,486 \\
\hline Chlorobium sp. & L227-2013-55 & 19.9 & $17.7-22.3$ & 78.9 & 48.5 & 2.38 & 2,338 \\
\hline Chlorobium sp. & L227-2013-22 & 19.9 & $17.7-22.3$ & 78.7 & 45.9 & 2.55 & 2,459 \\
\hline Chlorobium sp. & L227-S-6D & 18.9 & $16.8-21.3$ & 78 & 46.8 & 2.49 & 2,383 \\
\hline Chlorobium sp. & L227-2013-56 & 18.5 & $16.3-20.9$ & 77.6 & 43.9 & 2.89 & 1,991 \\
\hline Chlorobium sp. & L442-64 & 19.7 & $17.5-22.1$ & 78.1 & 48.3 & 1.9 & 1,851 \\
\hline Chlorobium phaeobacteroides & DSM 266 & 19.2 & $17-21.6$ & 77.6 & 48.4 & 3.13 & 2,819 \\
\hline Chlorobium sp. & N1 & 17.9 & $15.8-20.3$ & 77.6 & 61.5 & 2.37 & 2,284 \\
\hline
\end{tabular}

Reference genome identifiers correspond to isolates in Figure 1.

(Laufer et al., 2017) and the PSB R. iodosum and R. rubiginosum (Straub et al., 1999). R. palustris strain TIE-1 is able to oxidize thiosulfate, but no reports indicate the oxidation of sulfide by TIE-1 or closely related strains (Jiao et al., 2005; Schmidt et al., 2021). The ability to oxidize these sulfur compounds is also absent from the well-studied C. ferrooxidans strain KoFox (Heising et al., 1999). Genes implicated in sulfite oxidation, $a \operatorname{pr} A B$ and sat, were present in the " $\mathrm{Ca}$. C. masyuteum" genome but are likely also used for the assimilation of sulfur as no sulfite oxidation was observed. The sat genes are absent in other photoferrotrophic Chlorobium sp. (Thompson et al., 2017). No other sulfur oxidation genes were present.

In addition, the genome of " $\mathrm{Ca}$. C. masyuteum" contains cys, sat, and sir genes which participate in assimilatory sulfate reduction (ASR). Other photoferrotrophic Chlorobium sp. (e.g., C. phaeoferrooxidans, C. ferrooxidans, "Ca. C. canadense" L3046D, and L227 enrichment S-6D) have been shown to contain ASR genes, particularly cys (Thompson et al., 2017; Tsuji et al., 2020), and sulfate assimilation has been biochemically verified in the first two strains. During isolation of Chlorobium sp. strain N1, the authors suggested sulfate could be utilized as a sulfur source; however, ASR activity was not directly tested (Laufer et al., 2017).
Nitrogen fixation has been recognized in Chlorobium sp. for quite some time (Heda and Madigan, 1986; Bryant et al., 2012), and GSB may be important sources of fixed nitrogen in stratified water columns (Halm et al., 2009; Swanner et al., 2020). Although fixed nitrogen was always provided in the FW medium, the "Ca. C. masyuteum" genome does contain nifDKH genes encoding a Mo-requiring nitrogenase (Figure 5A). These genes have also been detected and growth without fixed nitrogen verified in the closely related photoferrotrophs C. ferrooxidans and C. phaeoferrooxidans (Thompson et al., 2017).

Genes necessary to fix carbon using the reverse tricarboxylic acid cycle typical for Chlorobium sp. are present in " $\mathrm{Ca}$. C. masyuteum" (Tang and Blankenship, 2010). The BLA1 enrichment was also able to grow with acetate. As acetate utilization is an unusual capability for organisms within the Chlorobiaceae family (Imhoff, 2014), it is possible that this mode of growth may have required some type of syntrophy with "Ca. P. ferreus," although acetate cultures were dominated by "Ca. C. masyuteum" based on Sanger sequencing. Other photoferrotrophic Chlorobium that are able to use acetate but only in coculture are Chlorobium ferrooxidans (strain KoFox) with Geospirillum sp. strain Kofum (Heising et al., 1999) and the closely related Chlorobium sp. obligately in coculture with 


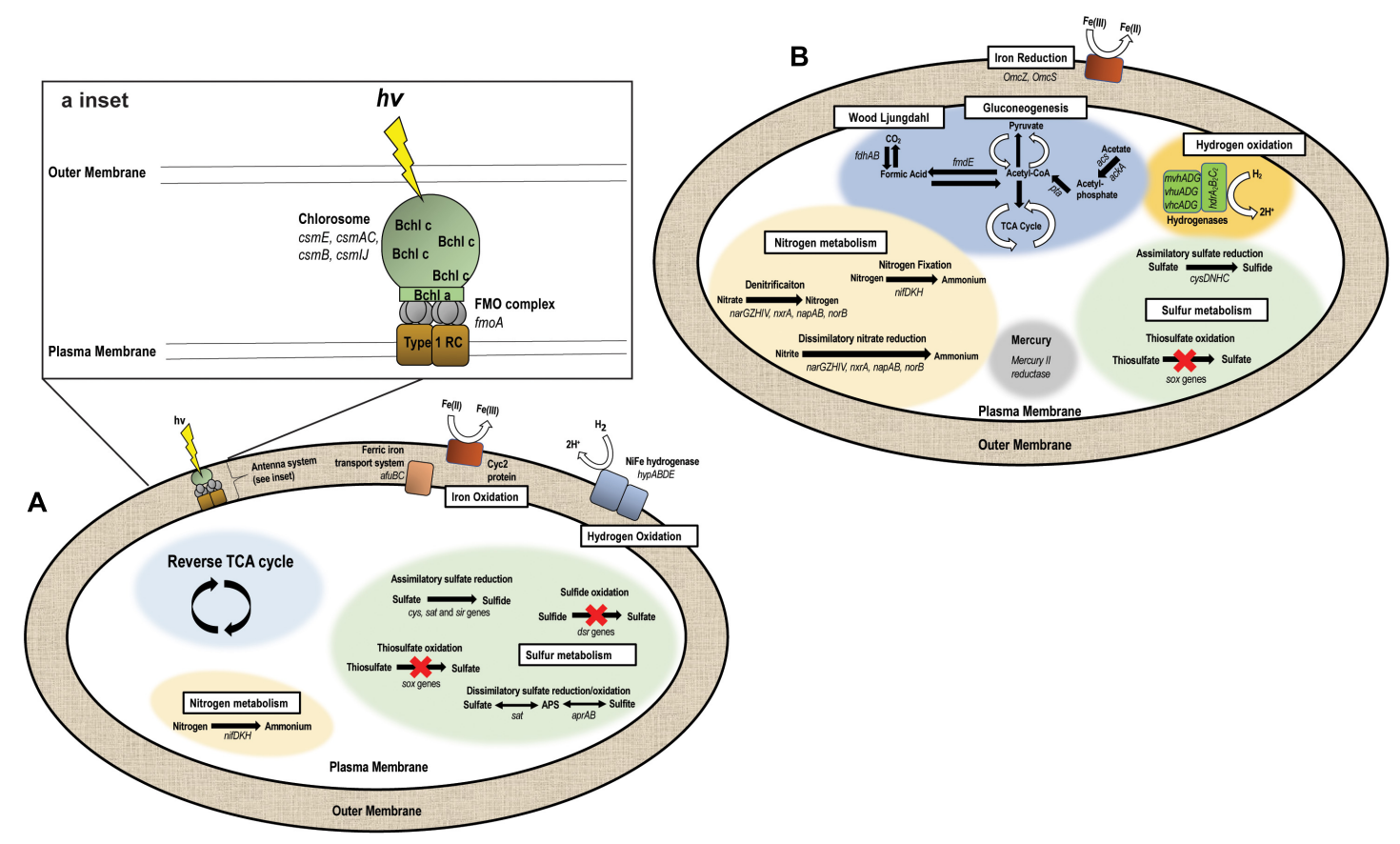

FIGURE 5 | Metabolic pathways encoded by the two genomes recovered from the BLA1 enrichment. (A) "Ca. C. masyuteum" (APS-adenylyl sulfate). Inset shows the antenna system (RC-reaction center, FMO-Fenna-Matthews-Olson, Bchl-Bacteriochlorophyll). (B) "Ca. P. ferreus."

acetate utilizing Rhodopseudomonas sp. (Schmidt et al., 2021). Considering we did observe robust growth dominated by " $\mathrm{Ca}$. C. masyuteum" on acetate, we suggest it could also be possible for "Ca. C. masyuteum" to use its reverse TCA cycle or run the reverse TCA in the forward direction to assimilate acetate, such as has been observed for C. tepidum (Tang and Blankenship, 2010).

Oxidation of $\mathrm{H}_{2}$ for photoautotrophic growth requires membrane-bound NiFe hydrogenases (Schwartz et al., 2006). The "Ca. C. masyuteum" genome contains hypABDE genes encoding for a Group 1d Ni-Fe hydrogenase (Figure 5A), similar to the genomes of $C$. ferrooxidans and C. phaoferrooxidans. This, along with growth experiments, suggests that " $\mathrm{Ca}$. C. masyuteum" is able to grow photoautotrophically utilizing $\mathrm{H}_{2}$. However, growth on $\mathrm{H}_{2}$ was not observed by $C$. phaoferrooxidans despite the presence of hyp genes (Thompson, 2020). Further work to establish whether hypABDE genes encode photosynthetic hydrogen oxidation may help to determine which genes can be used as genetic markers for photosynthetic hydrogen oxidation by GSB in environmental contexts (Thompson, 2020; Tsuji et al., 2020; Garcia et al., 2021).

\section{"Candidatus Pseudopelobacter ferreus"}

The "Ca. P. ferreus" genome is $4.5 \mathrm{Mb}$, consists of 139 contigs, with 4,019 predicted genes, and one 16S rRNA gene, and has a GC content of $54.6 \%$. Although it is not photosynthetic, this organism is metabolically flexible, with gene and protein families predicted to function in transformation of $\mathrm{C}, \mathrm{Fe}, \mathrm{N}, \mathrm{S}$, $\mathrm{H}$, and $\mathrm{Hg}$ (Figure 5B). The "Ca. P. ferreus" genome encodes for the reductive acetyl-CoA or Wood-Ljungdahl pathway for carbon fixation common among the Delta Proteobacteria (Hügler and Sievert, 2011).

"Ca. P. ferreus" seems likely to function as an FeRB when grown in the BLA1 enrichment, considering that the genome contains gene homologs for dissimilatory $\mathrm{Fe}$ (III) reduction and the detection of $\mathrm{Fe}(\mathrm{III})$ reduction activity in BLA1 after complete $\mathrm{Fe}(\mathrm{II})$ oxidation and acetate addition (Supplementary Figure 1). These homologs include omcS and $o m c Z$, putatively thought to be involved in long-distance extracellular electron transfer (Santos et al., 2015; Wang et al., 2019), and additional hypothetical proteins involved in electron transfer including porins, periplasmic cytochromes, and outermembrane cytochromes (Garber et al., 2020). The low abundance of the " $\mathrm{Ca}$. P. ferreus" genome in the BLA1 enrichment in combination with no subsequent Fe(III) reduction before acetate was added suggests that Fe(III) reduction is likely not occurring during photoferrotrophic growth in the absence of added electron donors.

$\mathrm{Fe}(\mathrm{III})$ reduction by " $\mathrm{Ca}$. P. ferreus" can likely be coupled to oxidation of $\mathrm{H}_{2}$. The genome encodes for the cytoplasmic heterodisulfide reductase (HdrABC) as well as a $\mathrm{NiFe}$ hydrogenase (MvhAGD). This complex seems to function in $\mathrm{H}_{2}$ oxidation and possibly electron bifurcation in a number of anaerobes, including methanogenic Archaea and Geobacter sulfurreducens (Wischgoll et al., 2005; Wagner et al., 2017). $\mathrm{Fe}$ (III) reduction activity with $\mathrm{H}_{2}$ was not assessed for BLA1.

Although it is capable of autotrophy, "Ca. P. ferreus" encodes multiple pathways for the incorporation of organics. Since BLA1 grew when amended with acetate, we have focused on possible pathways to explain this phenomenon (Figure 5B). Acetate could 


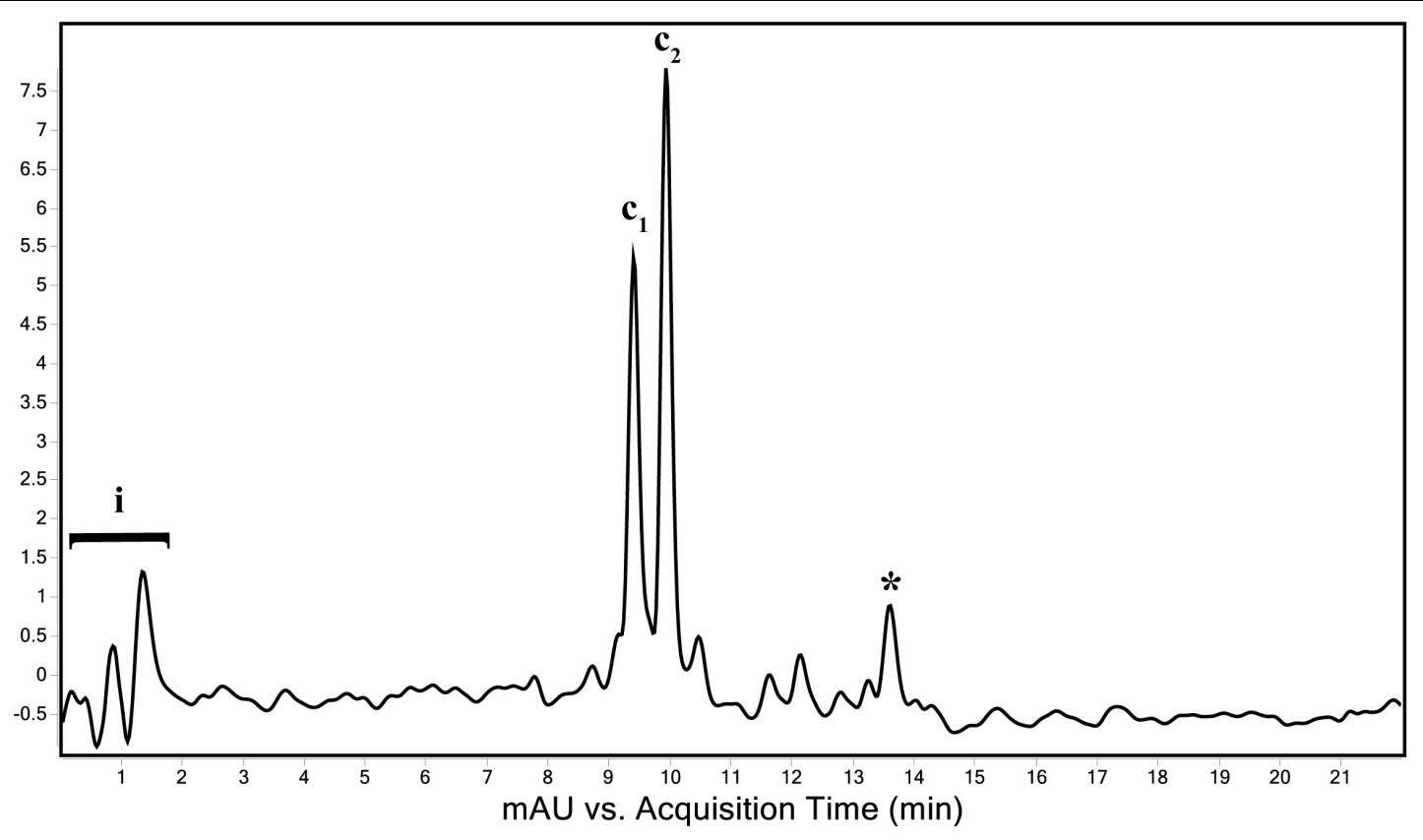

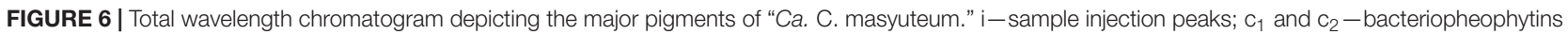
corresponding to bacteriochlorophyll c; *chlorobactene.

be incorporated as acetyl phosphate (via acs and ackA) and converted to acetyl-CoA ( $p t a)$. Acetyl-CoA could then feed into the TCA cycle or gluconeogenesis after conversion to pyruvate. Another possibility is that acetate is incorporated as acetyl-CoA by reversing the Wood-Ljungdahl pathway, such as occurs in some methanogens and anaerobes (Zhuang et al., 2014).

In addition to its potential role in $\mathrm{Fe}(\mathrm{III})$ reduction, the genome of " $\mathrm{Ca}$. P. ferreus" also encodes a mercury(II) reductase. Similar functionality has been detected in other Geobacterales (Lu et al., 2016). The genome also encodes for Mo-requiring nitrogenase via nifDKH and contained genes for ASR (i.e., cysDNHC).

\section{Pigments Produced by "Ca. C. masyuteum"}

The genome of "Ca. C. masyuteum" consisted of protein families for important minor pigments $\mathrm{Chl} a$ and $\mathrm{Bchl} a$, as well as the major light-harvesting pigment $\mathrm{Bchl} c$. To confirm that $\mathrm{Bchl} c$, as opposed to Bchl $d$ or $e$, is the major light-harvesting pigment, an extract from the BLA1 enrichment grown on $\mathrm{Fe}(\mathrm{II})$ was examined using a Q-TOF LC/MS system. The resulting chromatogram (Figure 6) displayed three major peaks corresponding to lightharvesting molecules. The first peak, denoted as $c_{1}$, eluted between 9.3 and $9.7 \mathrm{~min}$ and gave rise to a major ion at $m / z 785$ (Figure 7A). The second peak, denoted as $c_{2}$, eluted later between 9.9 and $10.2 \mathrm{~min}$ and displayed an increasing mass difference of $14 \mathrm{Da}(\mathrm{m} / \mathrm{z}$ 799; Figure 7B). Peaks of low relative abundance were detected in the mass spectra indicating the presence of numerous background ions. As "Ca. C. masyuteum" was the dominant organism under these growth conditions, and "Ca. P. ferreus" is non-photosynthetic, we interpret the detected pigments as sourcing from " $\mathrm{Ca}$. C. masyuteum."

Peaks $c_{1}$ and $c_{2}$ were identified as bacteriopheophytins (Bphes), suggestive of two structural isomers of Bchl $c$ based on previous identification with similar mass spectra (Airs and Keely, 2002). The detection of Bphes in place of Bchl $c$ is likely due to post-column demetallation of the center $\mathrm{Mg}^{2+}$ (Table 2; Airs and Keely, 2002). The verification of the Bphes peaks as derivatives of Bchl $c$ was assessed by performing a $\mathrm{MS}^{5}$ analysis, which creates fragmentation patterns unique to Bchl $c, d$, or $e$. The fragmentation pattern was as compared to work performed by Airs and Keely (2002) and indicative of Bchl $c$ (Supplementary Figure 2A). The corresponding UV/vis spectrum agreed with the $\mathrm{MS}^{5}$ analysis, which depicted major absorption peaks characteristic of Bchl $c$ at 412 and $668 \mathrm{~nm}$ (Supplementary Figure 2B). This is similar to what has been observed by Airs and Keely (2002). However, the peak at $412 \mathrm{~nm}$ is shifted to the left (412 nm instead of $435 \mathrm{~nm}$ ) of what was observed by Airs and Keely (2002), likely due to the loss of the $\mathrm{Mg}^{2+}$ ion. The utilization of Bchl $c$ as the main lightharvesting pigment is yet another feature that distinguishes "Ca. C. masyuteum" and its close relatives. C. ferroooxidans synthesizes Bchl $c$ as well (Heising et al., 1999). However, C. phaoferrooxidans synthesizes Bchl $e$ (Thompson, 2020).

The last of the major peaks eluted between 13.6 and $13.8 \mathrm{~min}$ (Figure 7). LC/MS analysis detected two molecules with overlapping retention times at this peak. Both molecules, $\gamma$-carotene and chlorobactene, likely contributed to the absorbance peak at $\sim 13.7 \mathrm{~min}$. However, MS/MS fragmentation revealed major ions for chlorobactene $[\mathrm{m} / \mathrm{z} 532.4$ (radical) and $\left.m / z 533 z 533.4\left(\mathrm{M}+\mathrm{H}^{+}\right)\right]$and minor ions for $\gamma$-carotene 


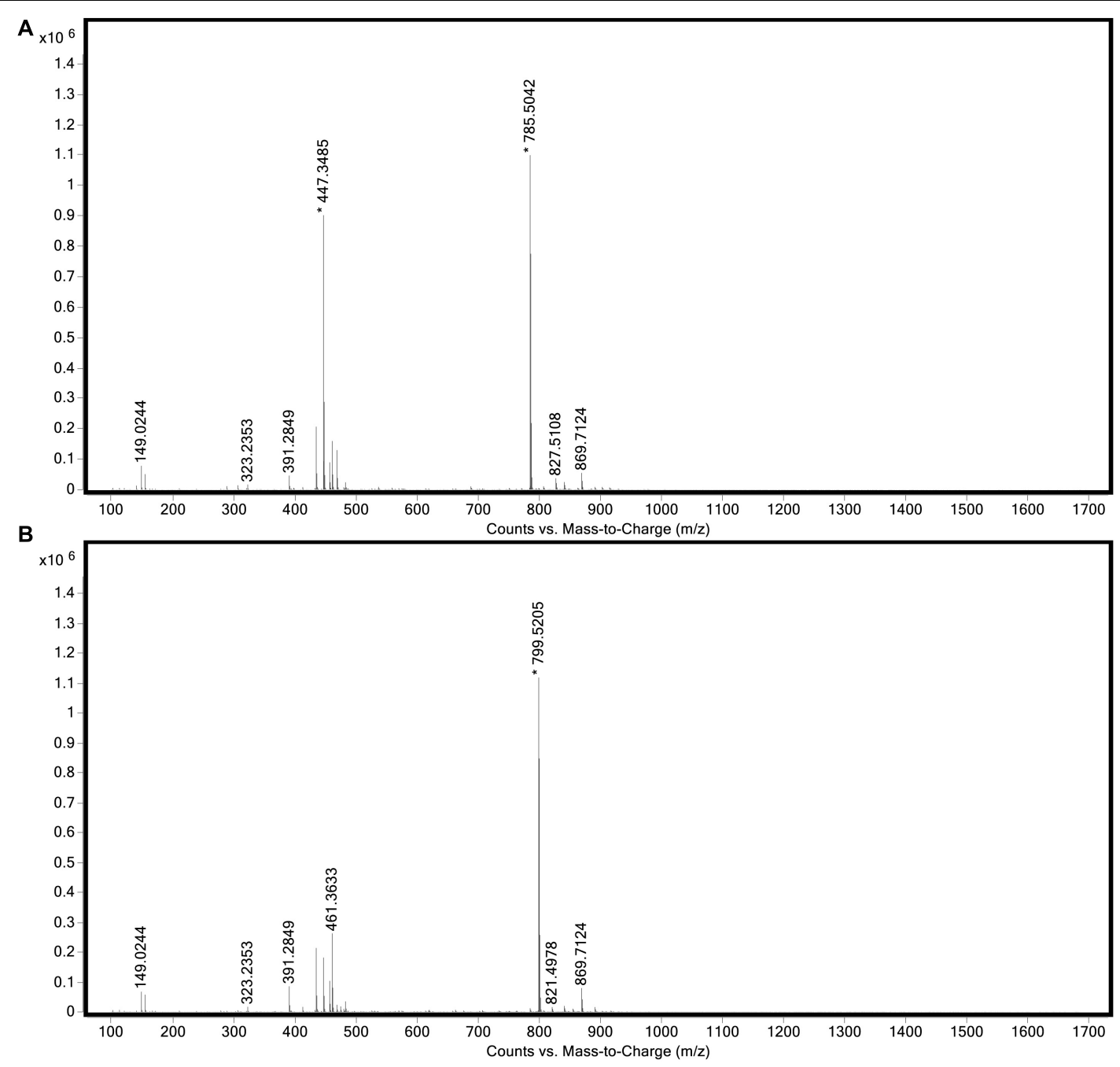

FIGURE 7 | Full mass spectra of $(\mathbf{A})$ peak $\mathrm{C}_{1}$ and $(\mathbf{B})$ peak $\mathrm{C}_{2}$ obtained during LC/MS analysis of the extract from "Ca. C. masyuteum."

$\left[m / z 536.4\right.$ (radical) and $m / z 537.4\left(\mathrm{M}+\mathrm{H}^{+}\right)$; Supplementary Figure $3 \mathbf{A}]$. The UV/vis spectrum of the major MS/MS fragmentation peak had three absorption maxima at 437, 460, and $488 \mathrm{~nm}$ (Supplementary Figure 3B). This sequence, when compared to reference absorption spectra (Jensen, 1965), corresponded to the aromatic carotenoid chlorobactene. The presence of both Bchl $c$ and the accessory pigment chlorobactene in the extract agrees with previous work on GSB (Maresca et al., 2008). A similar absorption spectrum for chlorobactene was observed in extracts from the photoferrotroph C. ferrooxidans strain KoFox (Hegler et al., 2008).

The activity of photoferrotrophs in ferruginous oceans prior to the GOE has been implicated in the formation of massive $\mathrm{Fe}-\mathrm{Si}$ deposits known as banded iron formations (BIF; Konhauser et al., 2002; Kappler et al., 2005; Hegler et al., 2008; Bekker et al., 2010; Mloszewska et al., 2012; Posth et al., 2013). However, ambiguity in assigning specific stable isotopic signatures exclusively to photoferrotrophy (e.g., Fe, see Swanner et al., 2015; Wu et al., 2017) indicates a need for other indicators of these organisms and their activity. Biomarkers are organic molecules that resist degradation and alteration and can be indicative of certain taxonomic groups (e.g., Bchl, aromatic carotenoids). Recent work has suggested that certain isoprenoids can act as biomarkers, linking APB to phototrophic $\mathrm{Fe}(\mathrm{II})$ oxidation in a Mesoproterozoic iron formation (Xiamaling Formation; $1.4 \mathrm{Ga}$ ) that shares similarities to Archean-aged BIFs (Canfield et al., 2018).

Chlorobactene exists as a monoaromatic carotenoid associated with green-pigmented GSB (i.e., Chlorobiaceae) and has been utilized as a proxy for GSB in the rock record as far back as $1.64 \mathrm{Ga}$ (e.g., Barney Creek Formation; Summons and Powell, 1986). The presence of chlorobactene in the Barney Creek Formation, as well as other Precambrian deposits mentioned previously, has typically signified euxinic conditions. However, GSB phototrophs such as " $\mathrm{Ca}$. C. masyutem" are capable of oxidizing iron but not reduced sulfur compounds (Table 1), and thus chlorobactene (or its derivatives) may not be a definitive indicator of euxinia. However, if found in 
combination with paleoredox proxies that indicate ferruginous conditions, detection of chlorobactene might serve as a line of evidence in support of photoferrotrophy. Continued effort is needed to better describe the environmental conditions under which sulfur vs. Fe(II)-oxidizing phototrophs are active, as cryptic phototrophic sulfur cycling has been detected in ferruginous environments (Crowe et al., 2014), and cryptic phototrophic iron cycling is noted from euxinic environments (Berg et al., 2016).

\section{CONCLUSION}

In summary, two novel organisms were co-enriched from ferruginous meromictic Brownie Lake, Minnesota, United States. The most abundant organism in the BLA1 enrichment is " $\mathrm{Ca}$. C. masyuteum," a photoferrotrophic GSB that is genetically and physiologically unique when compared to close relatives. It is able to grow photoautotrophically using $\mathrm{Fe}(\mathrm{II})$, and possibly acetate and $\mathrm{H}_{2}$. It produces bacteriochlorophyll $\mathrm{c}$ as well as chlorobactene. The presence of the cyc2 gene in " $\mathrm{Ca}$. C. masyuteum" adds compounding evidence that this gene can be used as a marker for $\mathrm{Fe}$ (II) oxidation in GSB in ferruginous environments. The lack of sulfur oxidation pathways in this organism or observed reduced sulfur oxidation in the enrichment suggests that it likely performs photoferrotrophy in the environment but may also be able to use fermentation by-products like $\mathrm{H}_{2}$ or organic acids as electron donors for photosynthesis. The genome also encodes for a Mo-utilizing nitrogenase, suggesting a role for alleviation of nitrogen fixation in the redoxcline of Brownie Lake (Swanner et al., 2020).

"Ca. C. masyuteum" could not be isolated, and metagenomic sequencing revealed that a novel and metabolically flexible organism comprised about $1 \%$ of the BLA1 enrichment. " $\mathrm{Ca}$. P. ferreus" is a putative FeRB that likely oxidizes acetate and/or $\mathrm{H}_{2}$. Two other photoferrotrophic GSB also live in defined coculture (Heising et al., 1999; Bryce et al., 2019), suggesting that close associations with other organisms may be a common strategy among photoferrotrophic GSB.

Description of "Candidatus Chlorobium masyuteum" (ma.syu.te for the phrase mas'yúte, meaning "eats iron" in the Dakota language spoken by the first caretakers of Brownie Lake). Short rod-like bacterium $(0.8 \mu \mathrm{m}$ by $0.4-0.6 \mu \mathrm{m}$ in size). Selective enrichment from freshwater at $20^{\circ} \mathrm{C}$ with a long-pass light filter (i.e., > $700 \mathrm{~nm}$ ). Grows autotrophically in freshwater medium with $\mathrm{Fe}$ (II) or molecular hydrogen as electron donors, in defined coculture with a Pseudopelobacter sp. Basis of assignment: digital DDH and ANI relatedness measures indicate a significant divergence at the genome to level from its closest Chlorobium relatives. Belongs to class Chlorobia, order Chlorobiales, and family Chlorobiaceae. Identified from a water sample of Brownie Lake, Minneapolis, Minnesota, United States.

Description of "Candidatus Pseudopelobacter ferreus" (fer're.us. L. masc. adj. ferreus pertaining to iron). Selective enrichment from freshwater at $20^{\circ} \mathrm{C}$. Grows in anoxic freshwater medium in defined coculture with "Ca. C. masyuteum." Basis of assignment: digital DDH and ANI relatedness measures indicate a significant divergence at the genome to level from its closest Pseudopelobacter relatives. Belongs to proposed phylum Desulfurbacterota, Desulfuromonadia class nov., Geobacterales order nov., and Pseudopelobacteraceae fam. nov. (Waite et al., 2020). Identified from a water sample of Brownie Lake, Minneapolis, Minnesota, United States.

\section{DATA AVAILABILITY STATEMENT}

The datasets presented in this study can be found in online repositories. The names of the repository/repositories and accession number(s) can be found in the article/ Supplementary Material.

\section{AUTHOR CONTRIBUTIONS}

NL, ZS, and ES wrote the manuscript with input from all authors. NL and ES collected the field samples. MP, NL, ZS, and HT conducted the laboratory experiments with the isolate. CS, ZS, and NL analyzed and annotated the genomes, and created the figures and tables for the manuscript.

\section{FUNDING}

This work was sponsored by the National Science Foundation (NSF) collaborative research grant (EAR-1660691 to ES and EAR-1660761 to CS). This work was also supported by the National Aeronautics and Space Administration (NASA) Interdisciplinary Consortium for Astrobiology Research grant 80NSSC21K0592, Metal Utilization and Selection across Eons (MUSE).

\section{ACKNOWLEDGMENTS}

Chad Wittkop and Sergei Katsev helped to collect water samples. We acknowledge the W. M. Keck Metabolomics Research Laboratory (Office of Biotechnology, Iowa State University) for providing analytical instrumentation and we thank Lucas Showman for his assistance and support. Tracey Stewart at the Roy J. Carver High Resolution Microscopy Facility at Iowa State University facilitated TEM sample preparation and imaging. Šišóka Dúta and Alexander Hall assisted with developing the species epithets. The Minneapolis Parks and Recreation Board supplied permits to work at Brownie Lake. This manuscript was originally part of a dissertation accepted by Iowa State University and edited for publication.

\section{SUPPLEMENTARY MATERIAL}

The Supplementary Material for this article can be found online at: https://www.frontiersin.org/articles/10.3389/fmicb.2021. 695260/full\#supplementary-material 


\section{REFERENCES}

Abràmoff, M. D., Magalhães, P. J., and Ram, S. J. (2004). Image processing with ImageJ. Biophotonics Int. 11, 36-42.

Airs, R. L., and Keely, B. J. (2002). Atmospheric pressure chemical ionisation liquid chromatography/mass spectrometry of bacteriochlorophylls from Chlorobiaceae: characteristic fragmentations. Rapid Commun. Mass Spectrom. 16, 453-461. doi: 10.1002/rcm.598

Altschul, S. F., Gish, W., Miller, W., Myers, E. W., and Lipman, D. J. (1990). Basic local alignment search tool. J. Mol. Biol. 215, 403-410.

Anantharaman, K., Brown, C. T., Hug, L. A., Sharon, I., Castelle, C. J., Probst, A. J., et al. (2016). Thousands of microbial genomes shed light on interconnected biogeochemical processes in an aquifer system. Nat. Comm. 7:13219. doi: 10 . 1038/ncomms13219

Barco, R. A., Emerson, D., Sylvan, J. B., Orcutt, B. N., Jacobson Meyers, M. E., Ramírez, G. A., et al. (2015). New insight into microbial iron oxidation as revealed by the proteomic profile of an obligate iron-oxidizing chemolithoautotroph. Appl. Environ. Microbiol. 81, 5927-5937. doi: 10.1128/ AEM.01374-15

Bekker, A., Slack, J. F., Planavsky, N., Krapez, B., Hofmann, A., Konhauser, K. O., et al. (2010). Iron formation: the sedimentary product of a complex interplay among mantle, tectonic, oceanic, and biospheric processes. Econ. Geol. 105, 467-508. doi: 10.2113/gsecongeo.105.3.467

Berg, J. S., Michellod, D., Pjevac, P., Martinez-Perez, C., Buckner, C. R. T., Hach, P. F., et al. (2016). Intensive cryptic microbial iron cycling in the low iron water column of the meromictic Lake Cadagno. Environ. Microbiol. 18, 5288-5302. doi: 10.1111/1462-2920.13587

Bóna-Lovász, J., Bóna, A., Ederer, M., Sawodny, O., and Ghosh, R. (2013). A rapid method for the extraction and analysis of carotenoids and other hydrophobic substances suitable for systems biology studies with photosynthetic bacteria. Metabolites 3, 912-930. doi: 10.3390/metabo3040912

Brocks, J. J., and Schaeffer, P. (2008). Okenane, a biomarker for purple sulfur bacteria (Chromatiaceae), and other new carotenoid derivatives from the 1640 Ma Barney Creek Formation. Geochim. Cosmochim. Acta 72, 1396-1414. doi: 10.1016/j.gca.2007.12.006

Brocks, J. J., Love, G. D., Summons, R. E., Knoll, A. H., Logan, G. A., and Bowden, S. A. (2005). Biomarker evidence for green and purple sulphur bacteria in a stratified Palaeoproterozoic sea. Nature 437:866. doi: 10.1038/nature04068

Bryant, D. A., and Liu, Z. (2013). Green bacteria: insights into green bacterial evolution through genomic analyses. Adv. Bot. Res. 66, 99-150.

Bryant, D. A., Liu, Z., Li, T., Zhao, F., Costas, A. M. G., Klatt, C. G., et al. (2012). "Comparative and functional genomics of anoxygenic green bacteria from the taxa chlorobi, chloroflexi, and acidobacteria," in Functional Genomics and Evolution of Photosynthetic Systems, eds R. Burnap and W. Vermaas (Dordrecht: Springer), 47-102. doi: 10.1007/978-94-007-1533-2_3

Bryce, C., Blackwell, N., Schmidt, C., Otte, J., Huang, Y. M., Kleindienst, S., et al. (2018). Microbial anaerobic Fe (II) oxidation-ecology, mechanisms and environmental implications. Environ. Microbiol. 20, 3462-3483. doi: 10.1111/ $1462-2920.14328$

Bryce, C., Blackwell, N., Straub, D., Kleindienst, S., and Kappler, A. (2019). Draft genome sequence of chlorobium sp. strain $\mathrm{N} 1$, a marine $\mathrm{Fe}(\mathrm{II})$-oxidizing green sulfur bacterium. Microbiol. Resour. Announc. 8, 1-2. doi: 10.1128/mra.0008019

Canfield, D. E., Rosing, M. T., and Bjerrum, C. (2006). Early anaerobic metabolisms. Philos. Trans. R. Soc. B Biol. Sci. 361, 1819-1836. doi: 10.1098/ rstb.2006.1906

Canfield, D. E., Zhang, S., Wang, H., Wang, X., Zhao, W., Su, J., et al. (2018). A mesoproterozoic iron formation. Proc. Natl. Acad. Sci. U.S.A. 115, E3895E3904.

Capella-Gutiérrez, S., Silla-Martínez, J. M., and Gabaldón, T. (2009). trimAl: a tool for automated alignment trimming in large-scale phylogenetic analyses. Bioinformatics 25, 1972-1973. doi: 10.1093/bioinformatics/btp348

Castelle, C., Guiral, M., Malarte, G., Ledgham, F., Leroy, G., Brugna, M., et al. (2008). A new iron-oxidizing/O2-reducing supercomplex spanning both inner and outer membranes, isolated from the extreme acidophile Acidithiobacillus ferrooxidans. J. Biol. Chem. 283, 25803-25811. doi: 10.1074/jbc.M802496200
Chan, C., McAllister, S. M., Garber, A., Hallahan, B. J., and Rozovsky, S. (2018). Fe oxidation by a fused cytochrome-porin common to diverse Fe-oxidizing bacteria. bioRxiv [Preprint]. doi: 10.1101/228056

Chaumeil, P.-A., Mussig, A. J., Hugenholtz, P., and Parks, D. H. (2019). GTDBTk: a toolkit to classify genomes with the genome taxonomy database. Bioinformatics 36, 1925-1927.

Chen, S., Zhou, Y., Chen, Y., and Gu, J. (2018). fastp: an ultra-fast all-in-one FASTQ preprocessor. Bioinformatics 34, i884-i890.

Chew, A. G. M. (2007). Elucidation of the Bacteriochlorophyll c Biosynthesis Pathway in Green Sulfur Bacterium Chlorobium Tepidum. State College, PA: The Pennsylvania State University.

Costas, A. M. G., Tsukatani, Y., Rijpstra, W. I. C., Schouten, S., Welander, P. V., Summons, R. E., et al. (2012). Identification of the bacteriochlorophylls, carotenoids, quinones, lipids, and hopanoids of "Candidatus chloracidobacterium thermophilum". J. Bacteriol. 194, 1158-1168. doi: 10.1128/JB.06421-11

Croal, L. R., Jiao, Y., and Newman, D. K. (2007). The fox operon from Rhodobacter strain SW2 promotes phototrophic Fe (II) oxidation in Rhodobacter capsulatus SB1003. J. Bacteriol. 189, 1774-1782. doi: 10.1128/jb.01395-06

Croal, L. R., Johnson, C. M., Beard, B. L., and Newman, D. K. (2004). Iron isotope fractionation by $\mathrm{Fe}$ (II)-oxidizing photoautotrophic bacteria. Geochim. Cosmochim. Acta 68, 1227-1242. doi: 10.1016/j.gca.2003.09.011

Crowe, S. A., Hahn, A. S., Morgan-Lang, C., Thompson, K. J., Simister, R. L., Llirós, M., et al. (2017). Draft genome sequence of the pelagic photoferrotroph Chlorobium phaeoferrooxidans. Genome Announc. 5:e01584-16.

Crowe, S. A., Maresca, J. A., Jones, C., Sturm, A., Henny, C., Fowle, D. A., et al. (2014). Deep-water anoxygenic photosynthesis in a ferruginous chemocline. Geobiology 12, 322-339. doi: 10.1111/gbi.12089

Dong, X., and Strous, M. (2019). An integrated pipeline for annotation and visualization of metagenomic contigs. Front. Genet. 10:999. doi: 10.3389/fgene. 2019.00999

Edgar, R. C. (2004). MUSCLE: multiple sequence alignment with high accuracy and high throughput. Nucleic Acids Res. 32, 1792-1797. doi: 10.1093/nar/gkh340

Ehrenreich, A., and Widdel, F. (1994). Anaerobic oxidation of ferrous iron by purple bacteria, a new type of phototrophic metabolism. Appl. Environ. Microbiol. 60, 4517-4526. doi: 10.1128/aem.60.12.4517-4526.1994

Eickhoff, M., Birgel, D., Talbot, H. M., Peckmann, J., and Kappler, A. (2013). Oxidation of F e (II) leads to increased C-2 methylation of pentacyclic triterpenoids in the anoxygenic phototrophic bacterium Rhodopseudomonas palustris strain TIE-1. Geobiology 11, 268-278. doi: 10.1111/gbi.12033

Fenna, R. E., Matthews, B. W., Olson, J. M., and Shaw, E. K. (1974). Structure of a bacteriochlorophyll-protein from the green photosynthetic bacterium Chlorobium limicola: crystallographic evidence for a trimer. J. Mol. Biol. 84, 231-240. doi: 10.1016/0022-2836(74)90581-6

Garber, A. I., Nealson, K. H., Okamoto, A., McAllister, S. M., Chan, C. S., Barco, R. A., et al. (2020). FeGenie: a comprehensive tool for the identification of iron genes and iron gene neighborhoods in genome and metagenome assemblies. Front. Microbiol. 11:37. doi: 10.3389/fmicb.2020.00037

Garcia, S. L., Mehrshad, M., Buck, M., Tsuji, J. M., Neufeld, J. D., McMahon, K. D., et al. (2021). Freshwater Chlorobia exhibit metabolic specialization among cosmopolitan and endemic populations. mSystems 6:e01196-20. doi: 10.1128/ mSystems.01196-20

Grice, K., Cao, C., Love, G. D., Böttcher, M. E., Twitchett, R. J., Grosjean, E., et al. (2005). Photic zone euxinia during the Permian-Triassic superanoxic event. Science 307, 706-709. doi: 10.1126/science. 1104323

Gurevich, A., Saveliev, V., Vyahhi, N., and Tesler, G. (2013). QUAST: quality assessment tool for genome assemblies. Bioinformatics 29, 1072-1075. doi: 10. 1093/bioinformatics/btt086

Halm, H., Musat, N., Lam, P., Langlois, R., Musat, F., Peduzzi, S., et al. (2009). Cooccurrence of denitrification and nitrogen fixation in a meromictic lake, Lake Cadagno (Switzerland). Environ. Microbiol. 11, 1945-1958. doi: 10.1111/j.14622920.2009.01917.x

Hays, L. E., Beatty, T., Henderson, C. M., Love, G. D., and Summons, R. E. (2007). Evidence for photic zone euxinia through the end-Permian mass extinction in the Panthalassic Ocean (Peace River Basin, Western Canada). Palaeoworld 16, 39-50. doi: 10.1016/j.palwor.2007.05.008 
He, S., Barco, R. A., Emerson, D., and Roden, E. E. (2017). Comparative genomic analysis of neutrophilic iron (II) oxidizer genomes for candidate genes in extracellular electron transfer. Front. Microbiol. 8:1584. doi: 10.3389/fmicb. 2017.01584

Heda, G. D., and Madigan, M. T. (1986). Aspects of nitrogen fixation in Chlorobium. Arch. Microbiol. 143, 330-336. doi: 10.1007/BF00412798

Hegler, F., Posth, N. R., Jiang, J., and Kappler, A. (2008). Physiology of phototrophic iron (II)-oxidizing bacteria: implications for modern and ancient environments. FEMS Microbiol. Ecol. 66, 250-260. doi: 10.1111/j.1574-6941. 2008.00592.x

Heising, S., Richter, L., Ludwig, W., and Schink, B. (1999). Chlorobium ferrooxidans sp. nov., a phototrophic green sulfur bacterium that oxidizes ferrous iron in coculture with a "Geospirillum" sp. strain. Arch. Microbiol. 172, 116-124. doi: $10.1007 / \mathrm{s} 002030050748$

Hug, L. A., Baker, B. J., Anantharaman, K., Brown, C. T., Probst, A. J., Castelle, C. J., et al. (2016). A new view of the tree of life. Nat. Microbiol. 1, 1-6. doi: 10.1038/nmicrobiol.2016.48

Hügler, M., and Sievert, S. M. (2011). Beyond the Calvin cycle: autotrophic carbon fixation in the ocean. Ann. Rev. Mar. Sci. 3, 261-289. doi: 10.1146/annurevmarine-120709-142712

Imhoff, J. F. (2014). “The family Chlorobiaceae," in The Prokaryotes: Other Major Lineages of Bacteria and The Archaea, eds E. Rosenberg, E. F. DeLong, S. Lory, E. Stackebrandt, and F. Thompson (Berlin: Springer), 501-514. doi: 10.1007/ 978-3-642-38954-2_142

Jain, C., Rodriguez-R, L. M., Phillippy, A. M., Konstantinidis, K. T., and Aluru, S. (2018). High throughput ANI analysis of $90 \mathrm{~K}$ prokaryotic genomes reveals clear species boundaries. Nat. Commun. 9:5114. doi: 10.1038/s41467-018-07641-9

Jensen, S. L. (1965). Bacterial carotenoids. Acta Chem. Scand. 19, 1025-1030.

Jiao, Y., and Newman, D. K. (2007). The pio operon is essential for phototrophic Fe (II) oxidation in Rhodopseudomonas palustris TIE-1. J. Bacteriol. 189, 17651773. doi: 10.1128/jb.00776-06

Jiao, Y., Kappler, A., Croal, L. R., and Newman, D. K. (2005). Isolation and characterization of a genetically tractable photoautotrophic Fe (II)-oxidizing bacterium, Rhodopseudomonas palustris strain TIE-1. Appl. Environ. Microbiol. 71, 4487-4496. doi: 10.1128/aem.71.8.4487-4496.2005

Jones, C., Nomosatryo, S., Crowe, S. A., Bjerrum, C. J., and Canfield, D. E. (2015). Iron oxides, divalent cations, silica, and the early earth phosphorus crisis. Geology 43, 135-138. doi: 10.1130/g36044.1

Kang, D. D., Froula, J., Egan, R., and Wang, Z. (2015). MetaBAT, an efficient tool for accurately reconstructing single genomes from complex microbial communities. PeerJ 3:e1165. doi: 10.7717/peerj.1165

Kang, D. D., Li, F., Kirton, E., Thomas, A., Egan, R., An, H., et al. (2019). MetaBAT 2: an adaptive binning algorithm for robust and efficient genome reconstruction from metagenome assemblies. PeerJ 7:e7359. doi: 10.7717/peerj.7359

Kappler, A., Bryce, C., Mansor, M., Lueder, U., Byrne, J. J. M., Swanner, E. E. D., et al. (2021). An evolving view on the biogeochemical iron cycle. Nat. Rev. Microbiol. 19, 360-374. doi: 10.1038/s41579-020-00502-7

Kappler, A., Pasquero, C., Konhauser, K. O., and Newman, D. K. (2005). Deposition of banded iron formations by anoxygenic phototrophic $\mathrm{Fe}(\mathrm{II})$ oxidizing bacteria. Geology 33, 865-868. doi: 10.1130/G21658.1

Konhauser, K. O., Hamade, T., Raiswell, R., Morris, R. C., Ferris, F. G., Southam, G., et al. (2002). Could bacteria have formed the Precambrian banded iron formations? Geology 30, 1079-1082. doi: 10.1130/0091-7613(2002)030<1079: cbhftp $>2.0 . \operatorname{co} ; 2$

Lambrecht, N., Wittkop, C., Katsev, S., Fakhraee, M., and Swanner, E. D. (2018). Geochemical characterization of two ferruginous meromictic lakes in the Upper Midwest, USA. J. Geophys. Res. Biogeosci. 123, 3403-3422. doi: 10.1029/ 2018jg004587

Lane, D. J. (1991). "16S/23S rRNA sequencing," in Nucleic Acid Techniques in Bacterial Systematics, eds E. Stackebrandt and M. Goodfellow (Chichester: John Wiley \& Sons), 115-174.

Laufer, K., Niemeyer, A., Nikeleit, V., Halama, M., Byrne, J. M., and Kappler, A. (2017). Physiological characterization of a halotolerant anoxygenic phototrophic Fe (II)-oxidizing green-sulfur bacterium isolated from a marine sediment. FEMS Microbiol. Ecol. 93:fix054.

Lee, M. D. (2019). GToTree: a user-friendly workflow for phylogenomics. Bioinformatics 35, 4162-4164. doi: 10.1093/bioinformatics/btz188
Llirós, M., García-Armisen, T., Darchambeau, F., Morana, C., Triadó-Margarit, X., Inceoð̋lu, Ö, et al. (2015). Pelagic photoferrotrophy and iron cycling in a modern ferruginous basin. Sci. Rep. 5:13803.

Lu, X., Liu, Y., Johs, A., Zhao, L., Wang, T., Yang, Z., et al. (2016). Anaerobic mercury methylation and demethylation by Geobacter bemidjiensis Bem. Environ. Sci. Technol. 50, 4366-4373. doi: 10.1021/acs.est.6b00401

Mallorquí, N., Arellano, J. B., Borrego, C. M., and García-Gil, L. J. (2005). Signature pigments of green sulfur bacteria in lower Pleistocene deposits from the Banyoles lacustrine area (Spain). J. Paleolimnol. 34, 271-280. doi: 10.1007/ s10933-005-3731-3

Maresca, J. A., Chew, A. G. M., Ponsatí, M. R., Frigaard, N. U., Ormerod, J. G., and Bryant, D. A. (2004). The bchU gene of Chlorobium tepidum encodes the C-20 methyltransferase in bacteriochlorophyll c biosynthesis. J. Bacteriol. 186, 2558-2566. doi: 10.1128/jb.186.9.2558-2566.2004

Maresca, J. A., Romberger, S. P., and Bryant, D. A. (2008). Isorenieratene biosynthesis in green sulfur bacteria requires the cooperative actions of two carotenoid cyclases. J. Bacteriol. 190, 6384-6391. doi: 10.1128/jb.00758-08

McAllister, S. M., Polson, S. W., Butterfield, D. A., Glazer, B. T., Sylvan, J. B., and Chan, C. S. (2020). Validating the Cyc2 neutrophilic iron oxidation pathway using meta-omics of zetaproteobacteria iron mats at marine hydrothermal vents. mSystems 5:e0553-19.

Meier-Kolthoff, J. P., Auch, A. F., Klenk, H.-P., and Göker, M. (2013). Genome sequence-based species delimitation with confidence intervals and improved distance functions. BMC Bioinformatics 14:60. doi: 10.1186/1471-2105-14-60

Melton, E. D., Swanner, E. D., Behrens, S., Schmidt, C., and Kappler, A. (2014). The interplay of microbially mediated and abiotic reactions in the biogeochemical Fe cycle. Nat. Rev. Microbiol. 12:797. doi: 10.1038/nrmicro3347

Mloszewska, A. M., Pecoits, E., Cates, N. L., Mojzsis, S. J., O’Neil, J., Robbins, L. J., et al. (2012). The composition of Earth's oldest iron formations: the Nuvvuagittuq Supracrustal Belt (Québec, Canada). Earth Planet. Sci. Lett. 317, 331-342. doi: 10.1016/j.epsl.2011.11.020

Morana, C., Roland, F. A. E., Crowe, S. A., Llirós, M., Borges, A. V., Darchambeau, F., et al. (2016). Chemoautotrophy and anoxygenic photosynthesis within the water column of a large meromictic tropical lake (Lake Kivu, East Africa). Limnol. Oceanogr. 61, 1424-1437. doi: 10.1002/lno.10304

Nguyen, L. T., Schmidt, H. A., Von Haeseler, A., and Minh, B. Q. (2015). IQ-TREE: a fast and effective stochastic algorithm for estimating maximum-likelihood phylogenies. Mol. Biol. Evol. 32, 268-274. doi: 10.1093/molbev/msu300

Nurk, S., Bankevich, A., Antipov, D., Gurevich, A., Korobeynikov, A., Lapidus, A., et al. (2013). "Assembling genomes and mini-metagenomes from highly chimeric reads," in Proceedings of the Annual International Conference on Research in Computational Molecular Biology, eds M. Deng, R. Jiang, F. Sun, and X. Zhang (Berlin: Springer), 158-170. doi: 10.1007/978-3-642-37195-0_13

Overmann, J., and Garcia-Pichel, F. (2013). "The phototrophic way of life BT - the prokaryotes: prokaryotic communities and ecophysiology," in The Prokaryotes, eds E. Rosenberg, E. F. DeLong, S. Lory, E. Stackebrandt, and F. Thompson (Berlin: Springer), 203-257. doi: 10.1007/978-3-642-30123-0_51

Parks, D. H., Imelfort, M., Skennerton, C. T., Hugenholtz, P., and Tyson, G. W. (2015). CheckM: assessing the quality of microbial genomes recovered from isolates, single cells, and metagenomes. Genome Res. 25, 1043-1055. doi: 10. $1101 /$ gr.186072.114

Posth, N. R., Konhauser, K. O., and Kappler, A. (2013). Microbiological processes in banded iron formation deposition. Sedimentology 60, 1733-1754. doi: 10.1111/ sed.12051

Poulton, S. W., and Canfield, D. E. (2011). Ferruginous conditions: a dominant feature of the ocean through Earth's history. Elements 7, 107-112. doi: 10.2113/ gselements.7.2.107

Raiswell, R., and Canfield, D. E. (2012). The iron biogeochemical cycle past and present. Geochem. Perspect. 1, 1-2. doi: 10.7185/geochempersp.1.1

Santos, T. C., Silva, M. A., Morgado, L., Dantas, J. M., and Salgueiro, C. A. (2015). Diving into the redox properties of Geobacter sulfurreducens cytochromes: a model for extracellular electron transfer. Dalt. Trans. 44, 9335-9344. doi: $10.1039 / \mathrm{c} 5 \mathrm{dt} 00556 \mathrm{f}$

Savvichev, A. S., Kokryatskaya, N. M., Zabelina, S. A., Rusanov, I. I., Zakharova, E. E., Veslopolova, E. F., et al. (2017). Microbial processes of the carbon and sulfur cycles in an ice-covered, iron-rich meromictic Lake Svetloe (Arkhangelsk region, Russia). Environ. Microbiol. 19, 659-672. doi: 10.1111/1462-2920.1 3591 
Schmidt, C., Nikeleit, V., Schaedler, F., Leider, A., Lueder, U., Bryce, C., et al. (2021). Metabolic responses of a phototrophic co-culture enriched from a freshwater sediment on changing substrate availability and its relevance for biogeochemical iron cycling. Geomicrobiol. J. 38, 267-281. doi: 10.1080/ 01490451.2020.1837303

Schwartz, E., Fritsch, J., and Friedrich, B. (2006). "The H2-metabolizing prokaryotes," in The Prokaryotes, eds M. Dworkin, S. Falkow, E. Rosenberg, K. H. Schleifer, and E. Stackebrandt (New York, NY: Springer), 496-563. doi: 10.1007/0-387-30742-7_17

Seemann, T. (2018). Barrnap 0.9: Rapid Ribosomal RNA Prediction. Available online at: https://github.com/tseemann/barrnap. (accessed January 2019).

Shaffer, M., Borton, M. A., McGivern, B. B., Zayed, A. A., La Rosa, S. L., Solden, L. M., et al. (2020). DRAM for distilling microbial metabolism to automate the curation of microbiome function. Nucleic Acids Res. 48, 8883-8900. doi: 10.1093/nar/gkaa621

Sieber, C. M. K., Probst, A. J., Sharrar, A., Thomas, B. C., Hess, M., Tringe, S. G., et al. (2018). Recovery of genomes from metagenomes via a dereplication, aggregation and scoring strategy. Nat. Microbiol. 3, 836-843. doi: 10.1038/ s41564-018-0171-1

Stookey, L. L. (1970). Ferrozine - a new spectrophotometric reagent for iron. Anal. Chem. 42, 779-781.

Straub, K. L., Rainey, F. A., and Widdel, F. (1999). Rhodovulum iodosum sp. nov. and Rhodovulum robiginosum sp. nov., two new marine phototrophic ferrousiron-oxidizing purple bacteria. Int. J. Syst. Evol. Microbiol. 49, 729-735. doi: 10.1099/00207713-49-2-729

Summons, R. E., and Powell, T. G. (1986). Chlorobiaceae in Palaeozoic seas revealed by biological markers, isotopes and geology. Nature 319:763. doi: $10.1038 / 319763 \mathrm{a} 0$

Swanner, E. D., Lambrecht, N., Wittkop, C., Harding, C., Katsev, S., Torgeson, J., et al. (2020). The biogeochemistry of ferruginous lakes and past ferruginous oceans. Earth-Science Rev. 211, 103430. doi: 10.1016/j.earscirev.2020. 103430

Swanner, E. D., Wu, W., Hao, L., Wüstner, M. L., Obst, M., Moran, D. M., et al. (2015). Physiology, $\mathrm{Fe}(\mathrm{II})$ oxidation, and Fe mineral formation by a marine planktonic Cyanobacterium grown under ferruginous conditions. Front. Earth Sci. 3:60. doi: $10.3389 /$ feart.2015.00060

Tang, K. H., and Blankenship, R. E. (2010). Both forward and reverse TCA cycles operate in green sulfur bacteria. J. Biol. Chem. 285, 35848-35854. doi: 10.1074/ jbc.M110.157834

Thompson, J. D., Gibson, T. J., and Higgins, D. G. (2003). Multiple sequence alignment using ClustalW and ClustalX. Curr. Protoc. Bioinformatics Chapter 2:Unit 2.3.

Thompson, K. J. (2020). Phototrophic Iron Oxidation and Implications for Biogeochemical Cycling in the Archean Eon. Vancouver, BC: University of British Columbia. doi: 10.14288/1.0392002

Thompson, K. J., Simister, R. L., Hahn, A. S., Hallam, S. J., and Crowe, S. A. (2017). Nutrient acquisition and the metabolic potential of photoferrotrophic Chlorobi. Front. Microbiol. 8:1212. doi: 10.3389/fmicb.2017.01212

Tsuji, J. M., Tran, N., Schiff, S. L., Venkiteswaran, J. J., Molot, L. A., Tank, M., et al. (2020). Anoxygenic photosynthesis and iron-sulfur metabolic potential of Chlorobia populations from seasonally anoxic Boreal Shield lakes. ISME J. 14, 2732-2747. doi: 10.1038/s41396-020-0725-0
Viollier, E., Inglett, P. W., Hunter, K., Roychoudhury, A. N., and Van Cappellen, P. (2000). The ferrozine method revisited: $\mathrm{Fe}(\mathrm{II}) / \mathrm{Fe}(\mathrm{III})$ determination in natural waters. Appl. Geochemistry 15, 785-790. doi: 10.1016/S0883-2927(99)00097-9

Wagner, T., Koch, J., Ermler, U., and Shima, S. (2017). Methanogenic heterodisulfide reductase (HdrABC-MvhAGD) uses two noncubane [4Fe4S] clusters for reduction. Science 357, 699-703. doi: 10.1126/science.aan 0425

Waite, D. W., Chuvochina, M., Pelikan, C., Parks, D. H., Yilmaz, P., Wagner, M., et al. (2020). Proposal to reclassify the proteobacterial classes deltaproteobacteria and oligoflexia, and the phylum thermodesulfobacteria into four phyla reflecting major functional capabilities. Int. J. Syst. Evol. Microbiol. 70, 5972-6016. doi: 10.1099/ijsem.0.004213

Walter, X. A., Picazo, A., Miracle, M. R., Vicente, E., Camacho, A., Aragno, M., et al. (2014). Phototrophic Fe (II)-oxidation in the chemocline of a ferruginous meromictic lake. Front. Microbiol. 5:713. doi: 10.3389/fmicb.2014.0 0713

Wang, F., Gu, Y., O’Brien, J. P., Yi, S. M., Yalcin, S. E., Srikanth, V., et al. (2019). Structure of microbial nanowires reveals stacked hemes that transport electrons over micrometers. Cell 177, 361-369. doi: 10.1016/j.cell.2019.03.029

Wischgoll, S., Heintz, D., Peters, F., Erxleben, A., Sarnighausen, E., Reski, R., et al. (2005). Gene clusters involved in anaerobic benzoate degradation of Geobacter metallireducens. Mol. Microbiol. 58, 1238-1252. doi: 10.1111/j.1365-2958.2005. 04909.x

Wu, W., Swanner, E. D., Hao, L., Zeitvogel, F., Obst, M., Pan, Y., et al. (2014). Characterization of the physiology and cell-mineral interactions of the marine anoxygenic phototrophic Fe (II) oxidizer Rhodovulum iodosum-implications for Precambrian Fe (II) oxidation. FEMS Microbiol. Ecol. 88, 503-515. doi: 10.1111/1574-6941.12315

Wu, W., Swanner, E. D., Kleinhanns, I. C., Schoenberg, R., Pan, Y., and Kappler, A. (2017). Fe isotope fractionation during Fe (II) oxidation by the marine photoferrotroph Rhodovulum iodosum in the presence of Si-implications for Precambrian iron formation deposition. Geochim. Cosmochim. Acta 211, 307321. doi: 10.1016/j.gca.2017.05.033

Wu, Y. W., Simmons, B. A., and Singer, S. W. (2016). MaxBin 2.0: an automated binning algorithm to recover genomes from multiple metagenomic datasets. Bioinformatics 32, 605-607. doi: 10.1093/bioinformatics/btv638

Zhuang, W.-Q., Yi, S., Bill, M., Brisson, V. L., Feng, X., Men, Y., et al. (2014). Incomplete Wood-Ljungdahl pathway facilitates one-carbon metabolism in organohalide-respiring Dehalococcoides mccartyi. Proc. Natl. Acad. Sci. U.S.A. 111, 6419-6424. doi: 10.1073/pnas.1321542111

Conflict of Interest: The authors declare that the research was conducted in the absence of any commercial or financial relationships that could be construed as a potential conflict of interest.

Copyright (c) 2021 Lambrecht, Stevenson, Sheik, Pronschinske, Tong and Swanner. This is an open-access article distributed under the terms of the Creative Commons Attribution License (CC BY). The use, distribution or reproduction in other forums is permitted, provided the original author(s) and the copyright owner(s) are credited and that the original publication in this journal is cited, in accordance with accepted academic practice. No use, distribution or reproduction is permitted which does not comply with these terms. 